Title:

\title{
A Novel Polymer-Derived-nanoCeramic for Ultrahigh Temperature MEMS Micro-igniter/Sensor
}

Final Scientific and Technical Report

Reporting Period:

October 01, 2003 to September 30, 2007

Principal Author:

Rishi Raj

Date of this Report:

July, 2008

Grant Award No: DE-FC26-03NT41967

Submitting Organization:

Department of Mechanical Engineering

University of Colorado at Boulder

Boulder, CO 80309-0427 
"This report was prepared as an account of work sponsored by an agency of the United States Government. Neither the United States Government nor any agency thereof, nor any of their employees, makes any warranty, express or implied, or assumes any legal liability or responsibility for the accuracy, completeness, or usefulness of any information, apparatus, product, or process disclosed, or represents that its use would not infringe privately owned rights.

Reference herein to any specific commercial product, process, or service by trade name, trademark, manufacturer, or otherwise does not necessarily constitute or imply its endorsement, recommendation, or favoring by the United States Government or any agency thereof. The views and opinions of authors expressed herein do not necessarily state or reflect those of the United States Government or any agency thereof." 


\begin{abstract}
Polymer-derived ceramics (PDCs) constituted from silicon, carbon, nitrogen and oxygen embody not only remarkable resistance to creep, thermal shock and oxidation at very high temperatures, but also functional properties such as semiconductivity which extends up to $1350^{\circ} \mathrm{C}$. In this report we describe the extraordinary sensitivity of the electrical resistance of the PDCs to hydrogen, at temperatures up to $1000^{\circ} \mathrm{C}$. Two types of structures: carbon-nanotube paper coated with a monolayer of PDCs (Type A), and free standing MEMS-scale PDC sensors (Type B) were studied. The first type of specimens showed a huge change in resistance when cycled between hydrogen and nitrogen; the sensitivity increased with temperature. The Type B specimens showed the opposite behavior, being more sensitive at the lower temperatures; nevertheless, these sensors showed reproducible and reversible change of resistance in the presence of hydrogen at temperatures up to $1000^{\circ} \mathrm{C}$. It is inferred that the response of Type $\mathrm{A}$ sensors was limited by kinetics, while that of Type B sensors was limited by the thermodynamic solubility of hydrogen in PDC materials. However, a more robust scientific understanding of the underlying chemical and nanostructural basis for PDC conductometric-sensors, is essential. The potential of Type B sensors may well constitute a new paradigm for the measurement of hydrogen gas activity at very high temperatures.
\end{abstract}




\section{Executive Summary}

The principal objective of this project was to investigate whether or not a new class of materials, called Polymer-derived ceramics (PDCs) constituted from silicon, carbon, nitrogen and oxygen, have the potential for use as hydrogen sensors at high temperatures. These sensors were to be of the conductometric type, where the electrical resistance of the sensor changes with adsorption of the gaseous chemical species. Two types of sensor architectures were investigated. In Type A, carbon nanotube paper, having a very high surface area, was coated with a monolayer of the PDC. In the second type, Type B, free standing, millimeter scale PDC sensors were designed and fabricated for experimental measurements. In both instances electrical interconnect technology was developed for measurements of electrical resistance from the four-point method at high temperatures. Type $B$ specimens were employed to measure the resistivity of the PDC samples as a function of temperature up to $1350^{\circ} \mathrm{C}$. A reactor was developed for measurement of the change in resistance at high temperatures (up to $1000^{\circ} \mathrm{C}$ ) when the environment is cycled between hydrogen and nitrogen. Mixtures of hydrogen and argon were used to vary the hydrogen activity in the reactor. Preparation of Type A and B specimens, development of the interconnects for four-point measurement of electrical resistance at high temperatures, and construction of the reactor for hydrogen sensing experiments - all were new techniques that had to be developed especially to meet the objectives of this grant.

The Type A sensors, called as the PDC-CNT sensors in this report, had metallic character, that is, their electrical resistance increased with temperature. These specimens possessed a very high surface area, in the range of $400-600 \mathrm{~m}^{2} \mathrm{~g}^{-1}$. The sensitivity of these to hydrogen continued increased exponentially as the temperature was raised. At $600^{\circ} \mathrm{C}$ the resistance of the sensor changed by a factor of $300 \%$ when the atmosphere was cycled between hydrogen and nitrogen. Experiments with hydrogen-argon mixtures, with hydrogen concentration ranging upwards from $5 \%$, gave a monotonic increase in the resistance with hydrogen activity. Indeed, the rate of change of resistance was highest at the lowest concentrations. The increase of sensitivity with temperature suggests a kinetic (as opposed to thermodynamic) limitation to the sensor-gas reaction. The time dependent change in the resistance with constant exposure to hydrogen also suggested a kinetic constraint. Constant heating rate experiments were performed to understand this kinetic behavior but the results were inconclusive, and require further work. The design of viable high temperature sensors of this type would require a good scientific understanding of the underlying kinetic mechanisms.

The Type B sensors, which were made in the form of millimeter scale ready-to-use MEMS devices, and called PDC-MEMS in the report behaved quite differently than the Type A sensors. The intrinsic electronic conductivity of PDC was measured using these specimens from ambient up to $1350^{\circ} \mathrm{C}$ in an inert environment. In contrast to Type A specimens, which were metallic, the Type B specimens were semiconducting, that is, their resistance decreased at higher temperatures. The sensor response to hydrogen, which was measured up to $1000^{\circ} \mathrm{C}$, also differed: the sensor resistance decreased at higher temperature, with the highest sensitivity being achieved at the ambient temperature. Nevertheless, the response was reproducible and well defined even at $1000^{\circ} \mathrm{C}$. These results were unexpected since the Type B specimens 
had a very low surface area: less than $2 \mathrm{~m}^{2} \mathrm{~g}^{-1}$. The results were assumed to imply that hydrogen could diffuse into the PDC material, even at ambient temperature, and interfere with the electronic structure of the material. We had neither expected nor thought of this possibility. It is inferred that the response of the Type B sensors was thermodynamically rather than kinetically limited, that is, the change in the resistance was related to the thermodynamic solubility of hydrogen in PDC. This conclusion is consistent with the decrease in the sensor response at higher temperatures, since the solubility of a gas into a solid usually decreases with temperature. These PDC-MEMS findings are the most striking and most important result from this investigation.

In addition to Type A and B sensors, thin film PDC specimens were also investigated. Thin films were prepared on zirconia substrates, and the change in the resistance was measured at $600^{\circ} \mathrm{C}$. The technique for thin film preparation could not be fully mastered, and the results were erratic. Nevertheless, in a few cases highly reversible and reproducible results for the change in resistance with hydrogen-nitrogen cycling could be obtained. The magnitude of the change and the sensor behavior was similar to the results obtained for the Type B specimens. However, in view of the findings described just above, it is not clear that the thin film geometry holds any advantage over the Type B architecture for sensors made from PDCs.

Finally, the Type A specimens were further coated with a monolayer of Pt and $\mathrm{Pd}$. The additional coating with the precious metal appeared to degrade the performance of the sensors. However, the Pt and Pd coated materials gave outstanding results as catalysts for hydrogen generation from aqueous solutions of sodium borohydride. 


\section{Experimental Methods}

This project was concerned with measurement of the multifunctional properties of polymer-derived-ceramics (PDCs) in the presence of hydrogen. The aim was to investigate how hydrogen influences the electrical and catalytic properties of these novel materials, especially at high temperatures.

The PDCs are new materials where the expertise for their synthesis, and for the characterization of their properties is still evolving. Furthermore, the objectives of this project was entirely experimental. Therefore, a very large fraction of the resources in this project had to be devoted to the development of experimental methods. These methods fell into two categories: (i) synthesis and preparation of samples with appropriate shape and nanostructure, and (ii) the measurement of properties in the presence of hydrogen. The methods developed under this grant are listed in Tables I and II: the first summarizes the sample preparation methods, and the second the experimental techniques developed for the measurement of high temperature electrical properties of the samples. These methods are described briefly in the following subsections.

\section{S1: Preparation of Carbon Nanotube Paper Coated with Polymer-Derived SiCN}

Carbon nanotube paper, with a thickness of approximately $100 \mu \mathrm{m}$ was prepared by dispersion of carbon nanotubes into an aqueous medium with a surfactant and ultrasonication. This CNT "ink" was then filter pressed to produce CNT-paper. The paper was coated with a monolayer of polymer-derived silicon carbonitride ( $\mathrm{SiCN}$ ) by dip coating in a $10 \mathrm{vol} \%$ solution of Cerase ${ }^{\mathrm{TM}}$ in acetone. The coated paper was then annealed in argon at $1100^{\circ} \mathrm{C}$. A micrograph of the coated paper is given in Fig. 1. The coated paper was found to have much greater sensitivity of hydrogen, as measured by the change in its electrical conductivity, than the uncoated paper. Furthermore, the uncoated paper gave results that were highly variable, in contrast to the high reproducibility of data from the coated CNT-paper.

Figure 1: Carbon-nanotube paper coated

with a monolayer of polymer derived

silicon carbonitride.

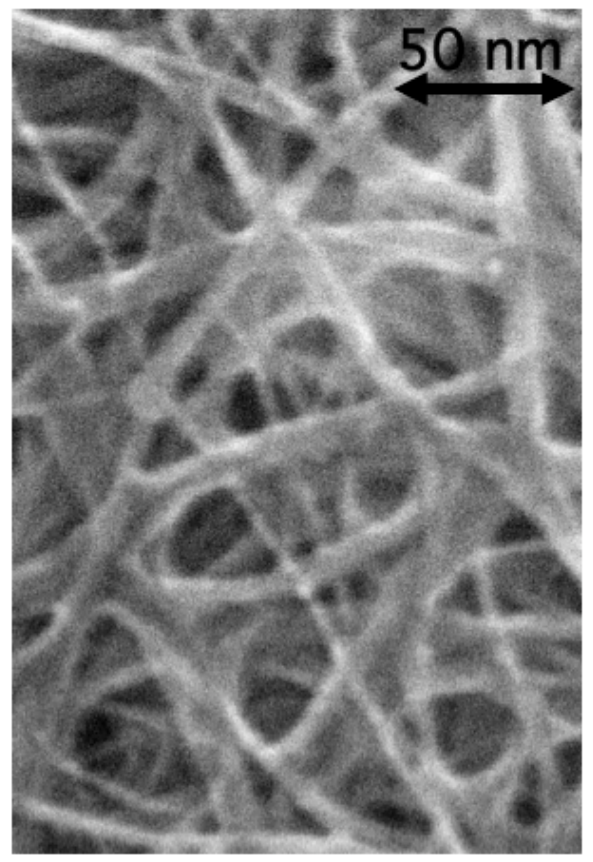


Table 1: Experimental Techniques Developed for Sample Preparation

\begin{tabular}{|c|c|c|}
\hline \multirow{2}{*}{ Item } & \multicolumn{2}{|c|}{ Development of Synthesis and Sample Preparation Methods } \\
\hline & Description, Approach and Why? & Special Achievement \\
\hline \multirow{2}{*}{$\mathbf{S 1 .}$} & $\begin{array}{l}\text { Carbon nanotube paper coated with a } \\
\text { monolayer of polymer derived } \\
\text { silicon carbonitride (PDC-CNT) }\end{array}$ & \multirow{2}{*}{$\begin{array}{l}\text { PDC-CNT paper with specific surface } \\
\text { area of } 400-600 \mathrm{~m}^{2} \mathrm{~g}^{-1} \text {, and with high } \\
\text { electrical conductivity were } \\
\text { developed for hydrogen sensing at } \\
\text { high temperatures, }\end{array}$} \\
\hline & $\begin{array}{l}\text { Why? The combined effect of high } \\
\text { surface area of CNT-Paper and PDC } \\
\text { functionalization expected to } \\
\text { increase hydrogen sensitivity. }\end{array}$ & \\
\hline \multirow{2}{*}{ s2. } & $\begin{array}{l}\text { Thin films of silicon carbonitride } \\
\text { PDC. }\end{array}$ & \multirow{2}{*}{$\begin{array}{l}\text { These experiments, while showing } \\
\text { high promise were plagued by a lack } \\
\text { of reproducibility, which, even } \\
\text { today remains a challenge. }\end{array}$} \\
\hline & $\begin{array}{l}\text { Why? The high surface area of thin } \\
\text { films and short diffusion distance } \\
\text { could enhance hydrogen sensitivity. }\end{array}$ & \\
\hline \multirow{2}{*}{ s3. } & $\begin{array}{l}\text { Free standing samples of "pure" } \\
\text { silicon carbonitride for four point } \\
\text { measurement of electrical } \\
\text { resistivity at high temperatures. }\end{array}$ & \multirow{2}{*}{$\begin{array}{l}\text { These specimens were } \sim 100 \mu \mathrm{m} \text { thick, } \\
\text { and had very low surface area (less } \\
\text { than } 5 \mathrm{~m}^{2} \mathrm{~g}^{-1} \text { ), but gave surprisingly } \\
\text { encouraging results for hydrogen } \\
\text { sensing. These results must be } \\
\text { followed up with further research } \\
\text { for high temperature hydrogen } \\
\text { sensors. }\end{array}$} \\
\hline & $\begin{array}{l}\text { Why? These samples were needed to } \\
\text { measure the intrinsic temperature } \\
\text { dependence of the electrical } \\
\text { resistivity of PDCs. }\end{array}$ & \\
\hline \multirow[b]{2}{*}{$\mathbf{S} 4$. } & $\begin{array}{l}\text { Samples as in } \mathrm{S} 1 \text { but coated with } \\
\text { monolayers of } \mathrm{Pt} \text { and Pd. }\end{array}$ & \multirow{2}{*}{$\begin{array}{l}\text { These samples were used to explore } \\
\text { their use as catalysts for the } \\
\text { generation of hydrogen from sodium } \\
\text { borohydride. Highly positive } \\
\text { results were obtained. }\end{array}$} \\
\hline & $\begin{array}{l}\text { Why? To study if hydrogen } \\
\text { sensitivity is enhanced, and to } \\
\text { study the potential for hydrogen } \\
\text { catalysis. }\end{array}$ & \\
\hline
\end{tabular}

\section{S2: Thin films of Silicon Carbonitride}

While the SiCN coated CNT paper showed significant sensitivity to its change in resistivity in the presence of hydrogen, the question remains whether the sensitivity was a result of the SiCN coating or the CNT paper. In order to resolve this issue, efforts were made to prepare thin films of SiCN and measure their sensitivity to hydrogen. After attempting several different kinds of substrates, yttria stabilized zirconia was found to be most suitable for film preparation. The electrical resistance of these thin film specimens exhibited a high sensitivity to hydrogen, but the results were not reproducible. This difficulty was attributed to variability in the surface roughness of the films. For example films deposited on an unpolished zirconia substrate gave a higher sensitivity that polished substrate. 


\section{S3: Free Standing Specimens of SiCN}

Specimens S1 and S2 were designed to have high surface area in the expectation that the sensitivity to hydrogen gas would necessarily require a specimen with a high surface area. However, it was also necessary to measure the intrinsic electrical resistivity of polymer-derived $\mathrm{SiCN}$, as a function of temperature. For this purpose small, millimeter sized, "H" shaped specimens were prepared by UV lithography. This shape provided a four point probe for the measurement of the resistance: while the current is controlled from the two legs on one side of the specimen, the voltage is measured at the legs on the other side. Finite element modeling was used to determine the geometrical correction factors for translating the measurements in to the resistivity. The samples were approximately $100 \mu \mathrm{m}$ thick.

The next challenge was to develop metallic interconnects that would survive at high temperatures. First, many different metal candidates having melting points higher than the temperatures where measurements were to be made, e.g. $\mathrm{Ni}, \mathrm{Ti}$, and $\mathrm{Mo}$, were mixed with the polymer-derived ceramics and then heat treated at high temperatures. The development of reaction products was monitored by $x$-ray diffraction. These results, as shown in Fig. 2. identified that Ti was the appropriate metal. It formed titanium-nitride upon reacting with $\mathrm{SiCN}$. TiN is an electrically conducting compound and it was found to remain stable up to $1400^{\circ} \mathrm{C}$ in a reducing environment. Techniques were then developed to make a junction between the SiCN and TiN on one side, and TiN and Pt wire on the other side. The platinum wires then served as the leads for the measurement of voltage and current. The process for forming the interconnects are shown in Fig. 3.

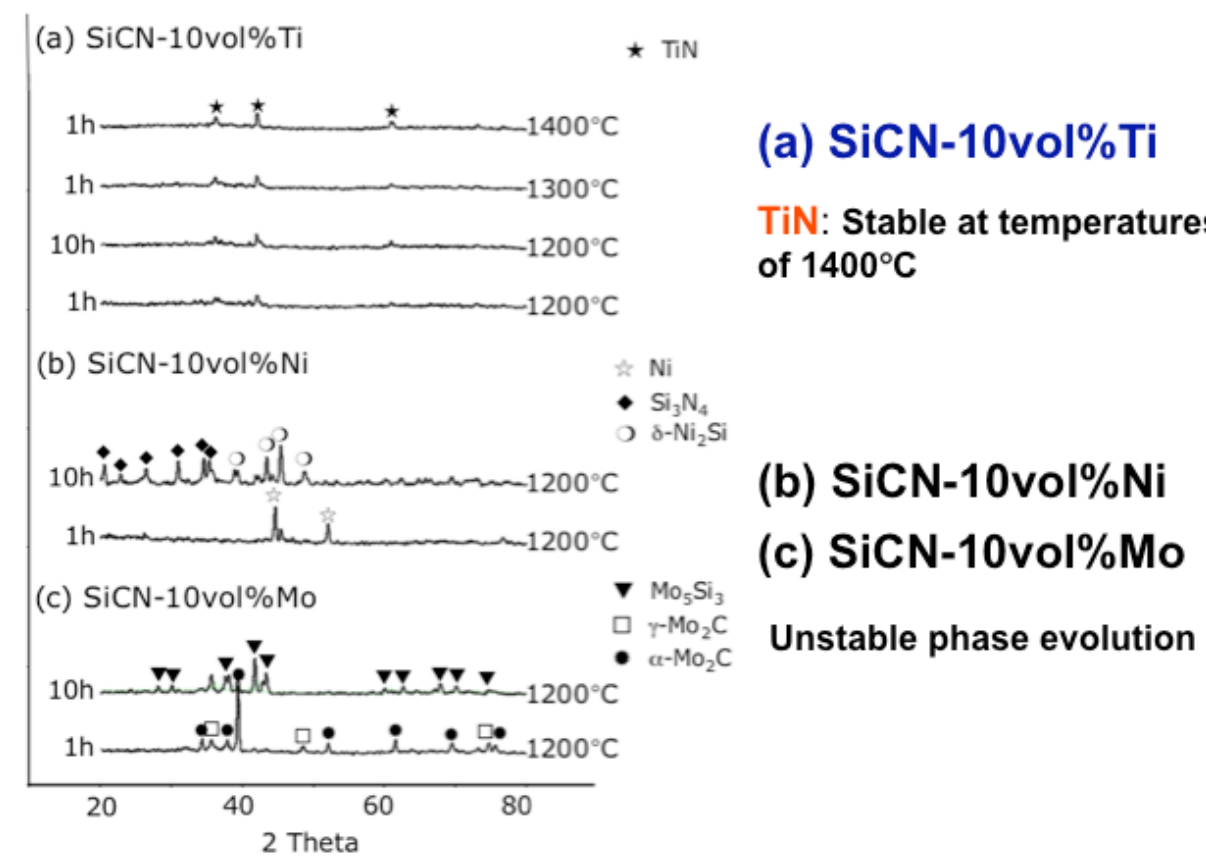

Figure 2: The materials for high temperature electrical interconnects were selected by reacting $\mathrm{Ti}, \mathrm{Ni}$ and $\mathrm{Mo}$ with $\mathrm{SiCN}$ at high temperature. As shown on the right, Ti was found to form TiN that remained stable up to $1400^{\circ} \mathrm{C}$. 


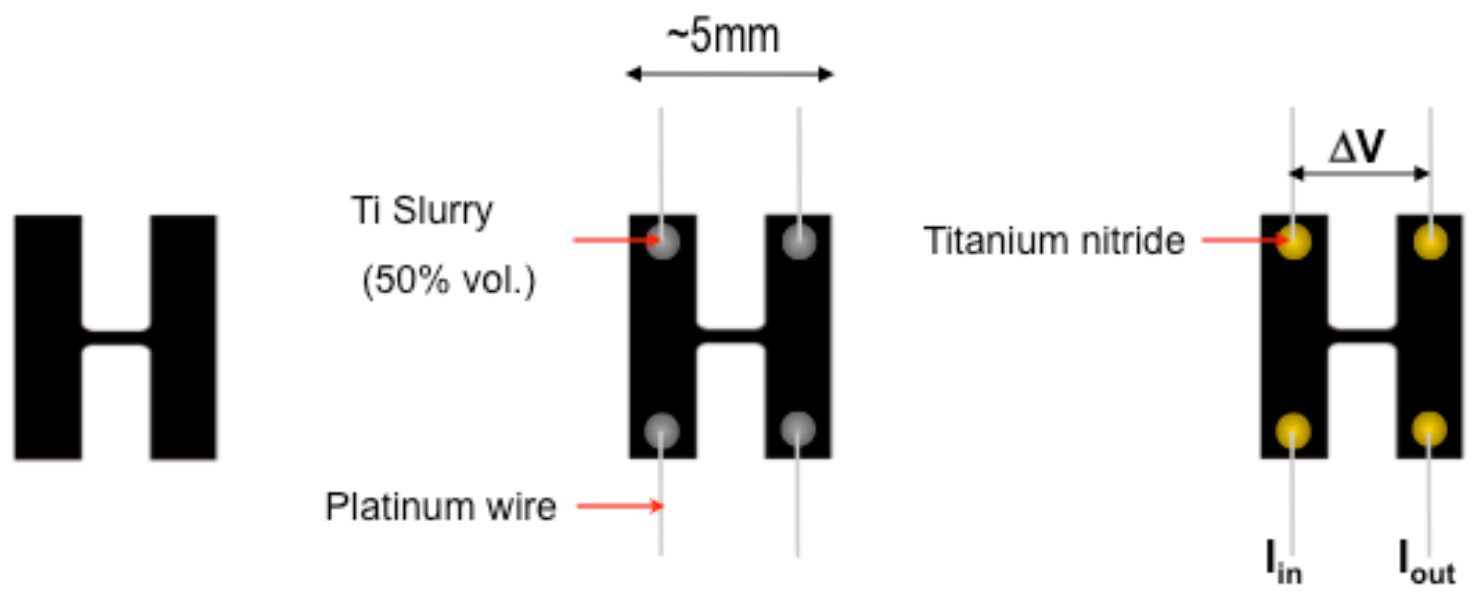

Figure 3: The "H"shaped specimens of SiCN prepared by UV lithography, and the process used to prepare electrical interconnects for the measurement of resistivity at high temperatures by the four-point method. The specimens were approximately $100 \mu \mathrm{m}$ thick.

\section{S4: PDC-CNT Paper Coated with a Monolayer of Pt and Pd}

As shown in the section on "Results" the PDC-CNT paper gave promising results in its sensitivity to hydrogen. We, therefore, became interested in its application as a catalyst for hydrogen generation from an alkaline solution of sodium borohydride. For this purpose a chemical method was developed for coating a monolayer of $\mathrm{Pt}$ and $\mathrm{Pd}$ on the surface if the catalyst, as shown schematically in Fig. 4 as the "picoscale" configuration of the metal atoms. This configuration greatly enhances the figure of merit for the catalyst since only the surface atoms are active in the catalytic mechanism. Nanoclusters of the metal atoms as shown on the left are wasteful of precious metal since the atoms lying within the nanocluster are inactive.

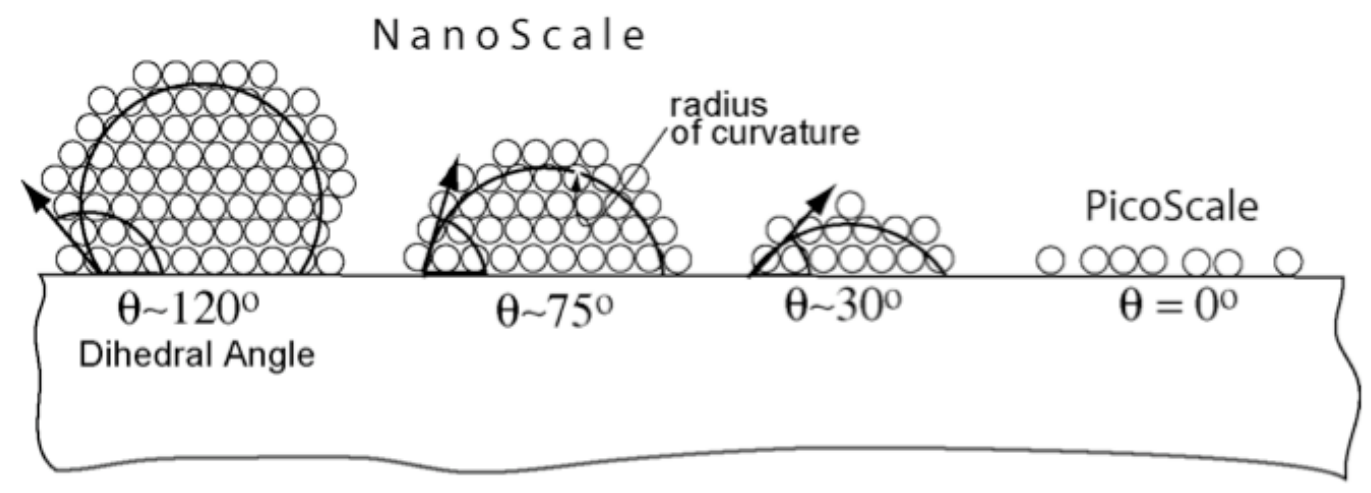

Figure 4. Top: The influence of the dihedral angle on the wetting behavior of metal atoms (Pt and Pd) on a surface. The PDC-CNT paper leads to the picoscale configuration which greatly enhances the catalytic efficiency of the metal atoms, because in the nanocluster configuration the atoms within the cluster do not contribute to catalytic activity. The picoscale configuration is hypothesized to occur because of the strong bonding between $\mathrm{Pt} / \mathrm{Pd}$ and the silicon atoms in the SiCN-PDC. 
Table 2: Experimental Techniques Developed for "Hydrogen" Measurements

\begin{tabular}{|c|c|c|}
\hline \multirow{2}{*}{ Item } & \multicolumn{2}{|c|}{ Development of Measurement Techniques } \\
\hline & Description & Achievement \\
\hline н1. & $\begin{array}{l}\text { Four-point measurement of } \\
\text { resistivity at very high } \\
\text { temperatures. }\end{array}$ & $\begin{array}{l}\text { The critical step in this technique } \\
\text { was the development of a reliable } \\
\text { metallic interconnects that could } \\
\text { survive temperatures as high as } \\
1400^{\circ} \mathrm{C}\left(2550^{\circ} \mathrm{F}\right) .\end{array}$ \\
\hline H2. & $\begin{array}{l}\text { Apparatus to measure hydrogen } \\
\text { sensitivity of the electrical } \\
\text { resistivity of samples at high } \\
\text { temperatures. }\end{array}$ & $\begin{array}{l}\text { This experiment successfully } \\
\text { addressed the challenge of } \\
\text { measuring the change in resistance } \\
\text { of small specimens (a few } \mathrm{mm} \text { ) at } \\
\text { high temperatures. }\end{array}$ \\
\hline н3. & $\begin{array}{l}\text { Apparatus to measure the catalytic } \\
\text { activity of CNT-PDC for hydrogen } \\
\text { generation from sodium borohydride. }\end{array}$ & $\begin{array}{l}\text { The apparatus required precise } \\
\text { temperature control in order to } \\
\text { achieve reproducibility. }\end{array}$ \\
\hline
\end{tabular}

\section{$\underline{\text { H1: Measurement of Resistivity at High Temperatures }}$}

The "H" shapes samples described in Fig. 3 were used to measure the resistivity of $\mathrm{SiCN}$ at high temperatures. The experimental set-up is given in Fig. 5. A Centorr furnace with tungsten elements was used. The experiments were carried out in an argon atmosphere. Measurements were made at from room temperature up to $1400^{\circ} \mathrm{C}$.

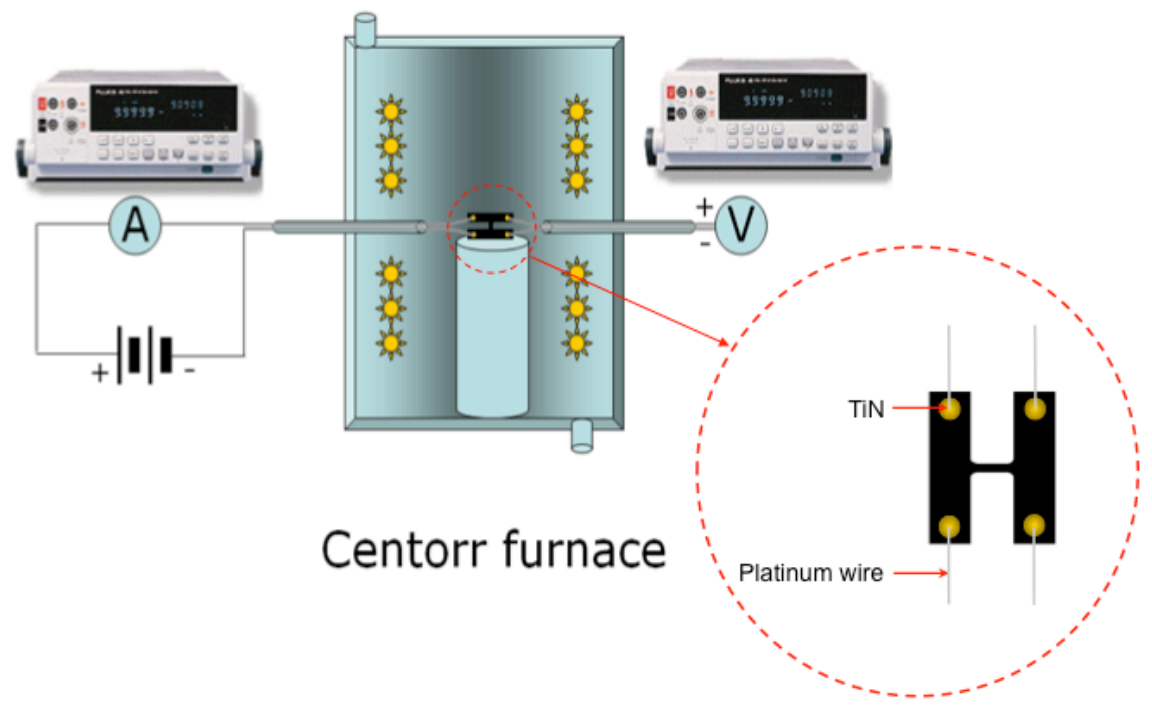

Figure 5: The apparatus that was developed for the measurement of the resistivity of SiCN-PDC at high temperatures. The furnace is heated with tungsten elements, and the experiments were carried out in argon atmosphere. 


\section{H2: Experiments to Measure the Hydrogen Sensitivity at High Temperatures}

The apparatus for these measurements was developed from grounds up. It included a furnace, a gas supply with mass-flow controllers, a four-point probe for electrical measurements from the sample, a reaction chamber with electrical feedthroughs and a data acquisition system (Fig. 6). Each of these tasks presented special challenges; among them the four-point probe was the most unconventional task which required significant innovation and ingenuity.

The furnace was designed to make measurements up to $1000^{\circ} \mathrm{C}$. The gas inputs could be varied between hydrogen, nitrogen, argon, and ambient air. Mixtures of hydrogen and argon were used to vary the hydrogen activity in the reactor. All experiments were carried out at ambient pressure. A mechanical vacuum pump was used to evacuate the reactor when the gas environment was changed.
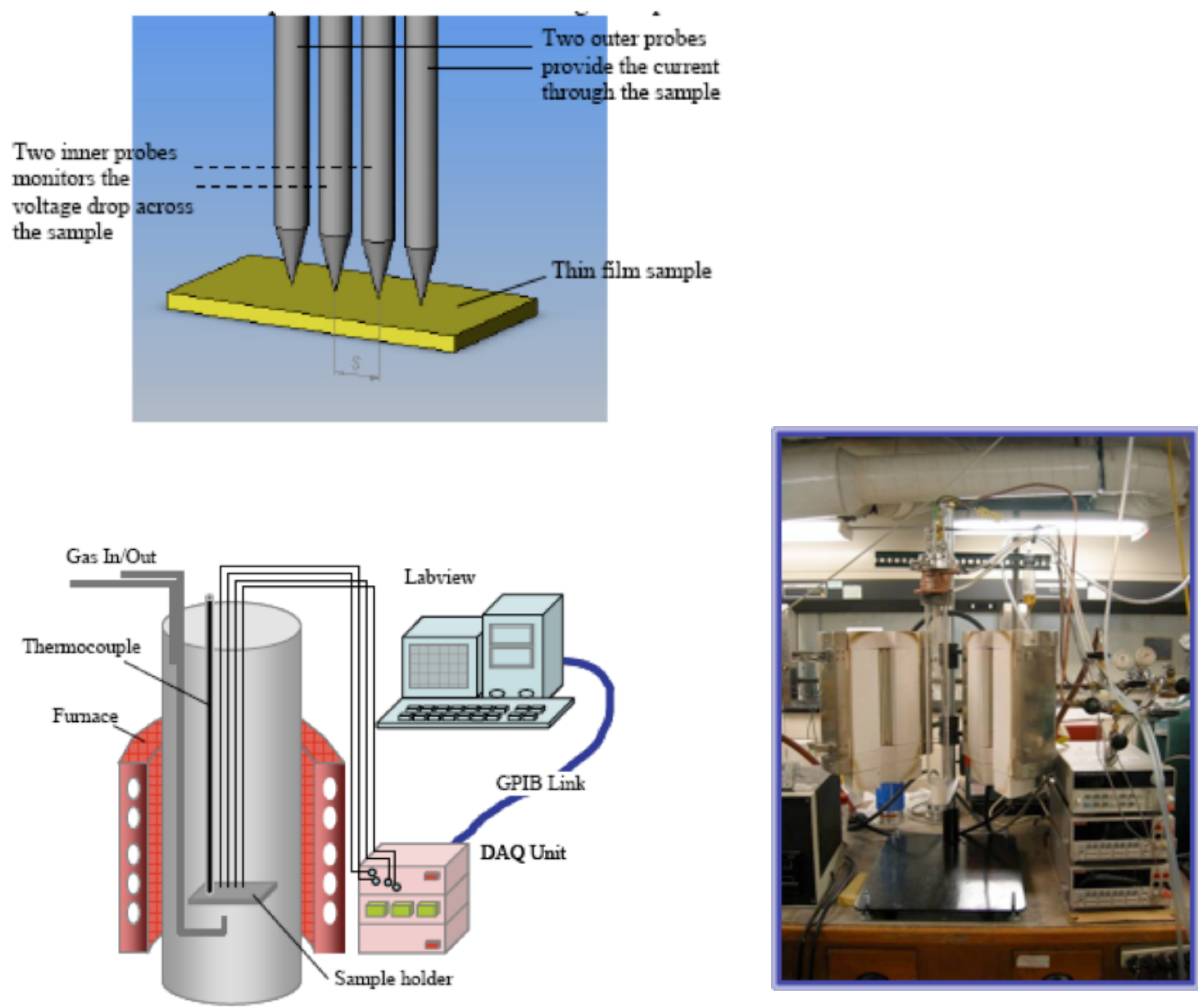

Figure 6: The experimental arrangement that was built for the measurement of the change in resistance at high temperatures in hydrogen, nitrogen, argon and ambient air environments. The development of the four-point probe, as shown schematically on the upper left, and in detail in Fig. 7 on the following page, required several iterations before success was achieved. 


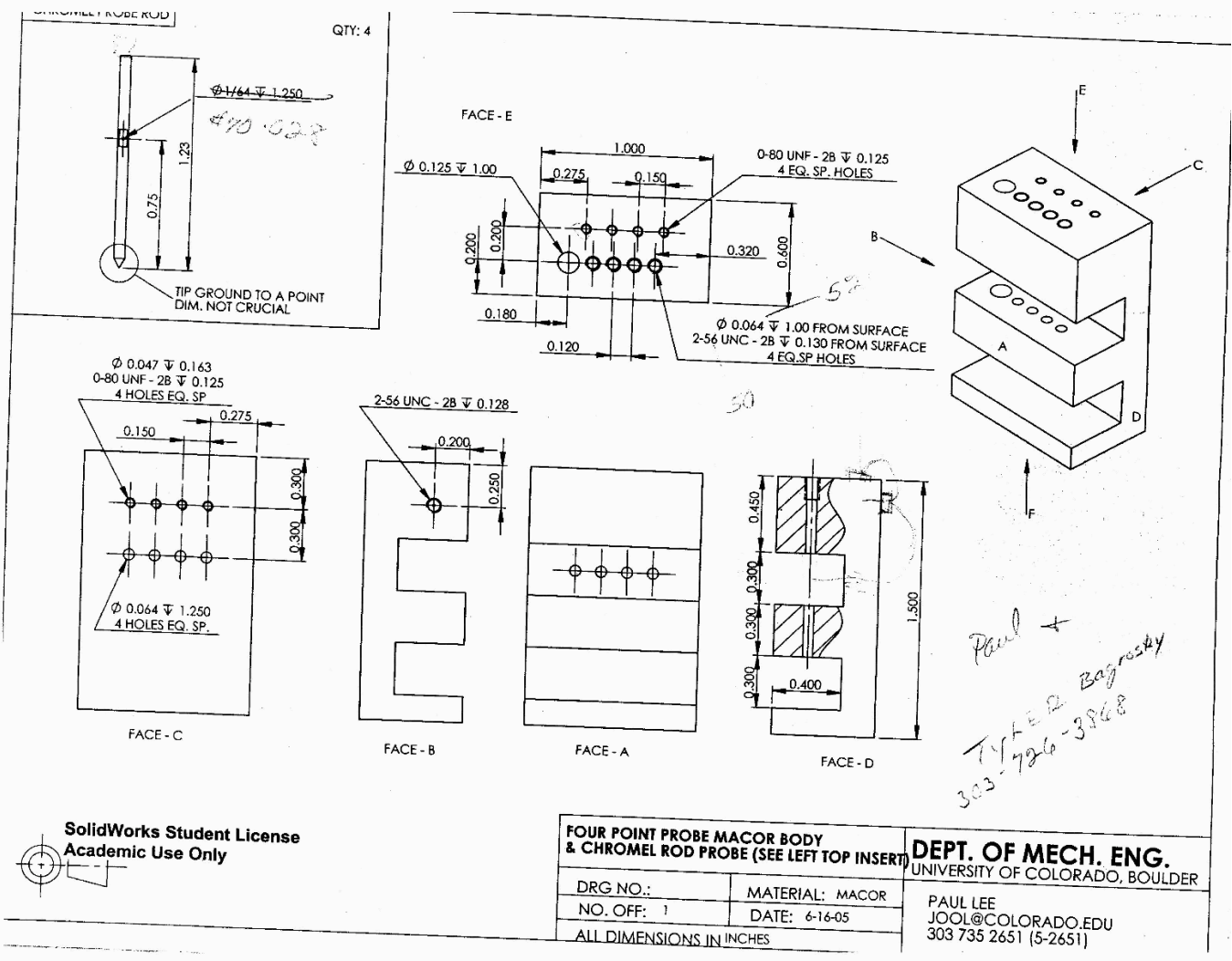

Figure 7: Detail of the four-point measurement probe shown schematically in Figure 6 on the previous page.

\section{H3: Apparatus for the Measurement of Hydrogen Catalytic Activity}

These experiments were developed to measure the rate of hydrogen generation from an alkaline solution of sodium borohydride using the catalyst prepared by the methods described in S4. The volume of hydrogen produced was measured as a function of time, using a gas burette connected to the reaction flask. Both the reactor and the burette were thermostated by a water circulating apparatus. The experiments were carried out at ambient pressure in Boulder, CO, which lies in the range $760 \pm 8 \mathrm{~mm}$ $x$ 0.854. The sodium borohydride solution was stirred with a magnetic spin bar at 800 rpm to promote interface-controlled reaction between the solution and the catalyst. All experiments were carried out with an amount of $\mathrm{NaBH}_{4}$ solution that would have a theoretical yield of $18 \mathrm{ml}$ of hydrogen at NTP. Four solution concentrations of $\mathrm{NaBH}_{4}$, $0.03,0.02,0.015$ and $0.01 \mathrm{M}$, were prepared. The solutions were buffered at $\mathrm{pH} 13$ with $\mathrm{KCl} / \mathrm{NaOH}$. Fresh solutions were prepared immediately before every hydrogen generation experiment. In all experiments the theoretically predicted conversion of $\mathrm{NaBH}_{4}$ into hydrogen was achieved. The experiments with the four molar concentrations 
were carried out at $29^{\circ} \mathrm{C}$. Additionally, experiments were done at $40^{\circ} \mathrm{C}, 50^{\circ} \mathrm{C}$, and $59^{\circ} \mathrm{C}$ at $0.03 \mathrm{M}$ in order to determine the activation energy for the catalytic reaction. 


\section{Results and Discussions}

Overview

The flow chart given in Fig. 8 summarizes the experiments that were carried out to determine the sensitivity of PDC-SiCN based samples to hydrogen.

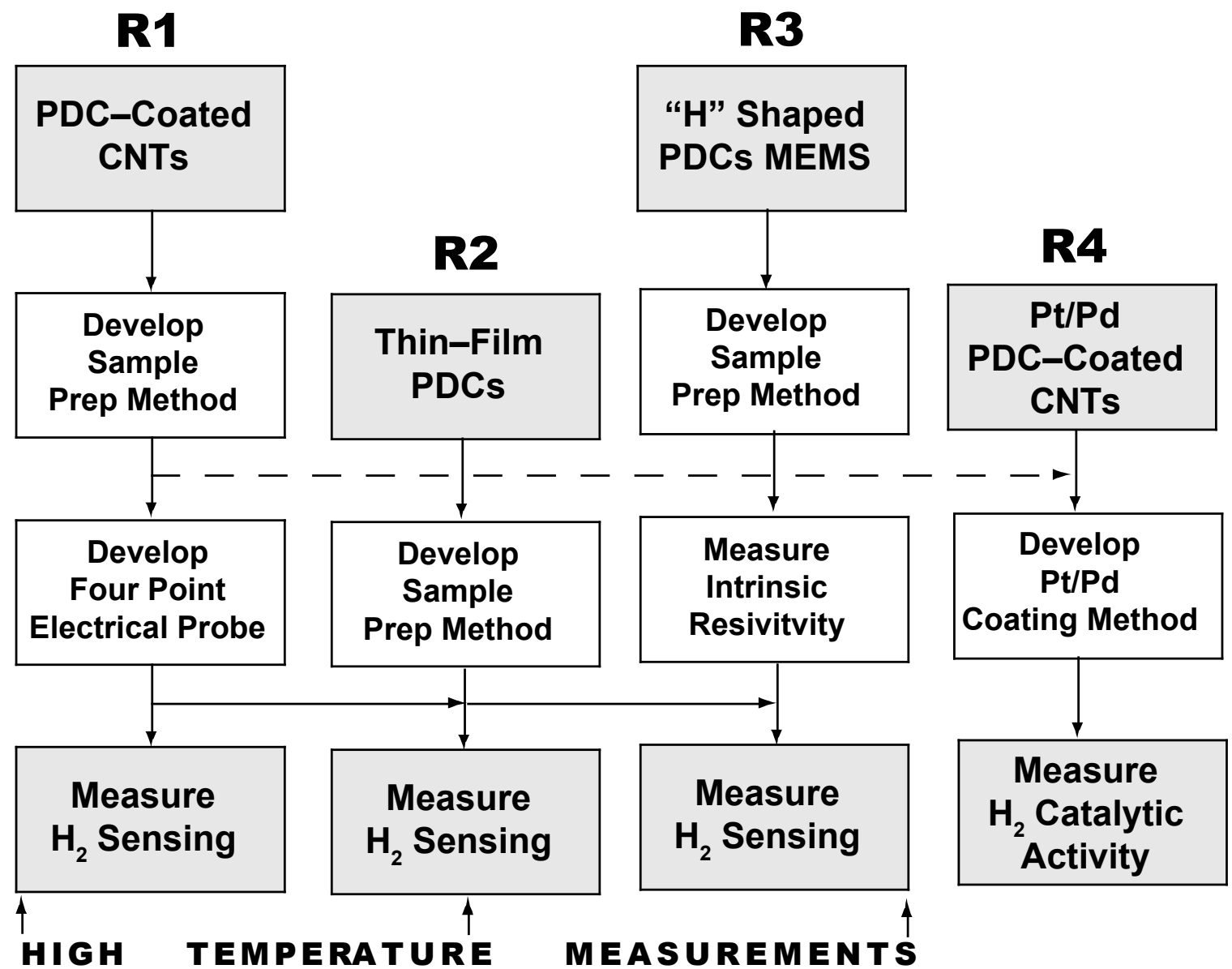

Figure 8: The types of samples and the measurements executed in this program. Broadly the experiments divide into two categories: (i) The high surface area specimens (PDC-Coated CNTs, R1 \& R4, and the thin film experiments, R2, and (ii) The PDC-MEMS specimens where the bulk behavior is measured. The second type of experiments were designed to measure the intrinsic electrical conductivity of SiCN-PDC, but unexpectedly also showed a high sensitivity to hydrogen suggesting fast diffusion transport of hydrogen into and out of the specimens - this was perhaps the most significant finding in this project, which needs to be pursued further.

The flow chart lists four sets of experiments, which broadly divide into two categories: those with sample having a high surface area, and those with bulk specimens of SiCN-PDCs. The bulk specimens were in the shape of MEMS (the " $\mathrm{H}$ " shaped specimens shown in Fig. 3); the specimens were fully dense as determined by BET-nitrogen adsorption experiments. The thickness of these " $\mathrm{H}$ " shaped specimens 
was approximately $100 \mu \mathrm{m}$. Experiments described as R3 were carried out with the "H" shaped specimens.

In contrast the other specimens had a high surface area, and were of two types. One type consisted of CNT paper, which was coated, with a monolayer of SiCN-PDC. These specimens has a specific surface area in the range of $300-600 \mathrm{~m}^{2} \mathrm{~g}^{-1}$. The second type was in the form of a thin film of PDC, about $600 \mathrm{~nm}$ thick, that was deposited on a zirconia substrate. The experiments in the R1 column were carried out with CNT-PDC paper, while the thin film structure was used for the R2 experiments. In R4 the CNT-PDC paper was further coated with a sub-monolayer of Pt/Pd in order to investigate its behavior as a catalyst for hydrogen.

The results from the above experiments are described and discussed in the following four subsections. Most of our effort to measure hydrogen sensitivity at high temperatures were devoted to the high surface area specimens (R1, R2 and R4). The " $\mathrm{H}$ " shaped specimens, belonging to the "bulk" category, were devoted to the measurement of the intrinsic electronic conductivity of the PDCs.

In the closing phase of this project it was decided to probe whether the bulk specimens could be sensitive to hydrogen. The most surprising, unexpected, and possibly the most significant result of this study was that the electrical conductivity of the bulk specimens showed significant sensitivity to hydrogen at temperatures up to $1000^{\circ} \mathrm{C}$. This discovery could lead to the development of robust high temperature sensors for hydrogen. The finding also raises the scientific question of the diffusivity of hydrogen into bulk specimens of polymer derived SiCN.

\section{R1: Hydrogen Sensitivity of PDC-Coated CNTs and Related Sensors}

\section{R1.1: Overview of the Experimental Variables:}

In these experiments the effect of environment on the change in the electrical resistance of CNT-paper was measured. The experiments were carried out from $100^{\circ} \mathrm{C}$ up to $600^{\circ} \mathrm{C}$. In addition to hydrogen, the influence of nitrogen, carbon-monoxide, and methane on the resistivity was measured; these experiments were carried out at 1 bar. In cycling experiments, where the atmosphere was changed from one species to another, the reactor was first evacuated before introducing the new gaseous species. The influence of evacuation with a mechanical pump on the resistivity was also characterized: this condition is described as "vacuum" and refers to a pressure of 1 to 10 torr.

Three types of CNT sensors were prepared, and are labeled as follows:

- UC-CNT: These were uncoated CNT-paper specimens. They had a surface area of $600-700 \mathrm{~m}^{2} \mathrm{~g}^{-1}$.

- PDC-CNT: These specimens were coated with a monolayer of polymer derived ceramic coating made from SiCN. These samples had a surface area of $400-600 \mathrm{~m}^{2} \mathrm{~g}^{-1}$. 
- $\quad$ Pd-PDC-CNT: These specimens were further coated with a monolayer of mixed $\mathrm{Pd}$ and $\mathrm{Pt}$.

The typical electrical resistance of the samples was $1 \mathrm{~K} \Omega$. The change in the resistivity with the environment is reported in relative terms, with 100 being the baseline, usually measured at the starting point in the experiment.

The results below show a dramatic change in the resistance of the PDC-CNT sensors upon exposure to hydrogen. The resistance changes by up to $300 \%$, and the sensitivity increase at higher temperatures. The selectivity of the response relative to $\mathrm{CO}$, and $\mathrm{CH}_{4}$ however remains an issue, although the signature of the sensor response is different for different gaseous species.

Measurements with different partial pressure of hydrogen (with the remaining gas being $\mathrm{Ar}$ ) showed a linear effect of the hydrogen concentration on the change in the resistance of PDC-CNT sensors.

In comparison to PDC-CNT the response of plain CNTs and Pd-PDC-CNT specimens was much weaker, with the resistance changing by less than $10 \%$.

R1.2: Hydrogen Sensitivity of PDC-CNT Sensors

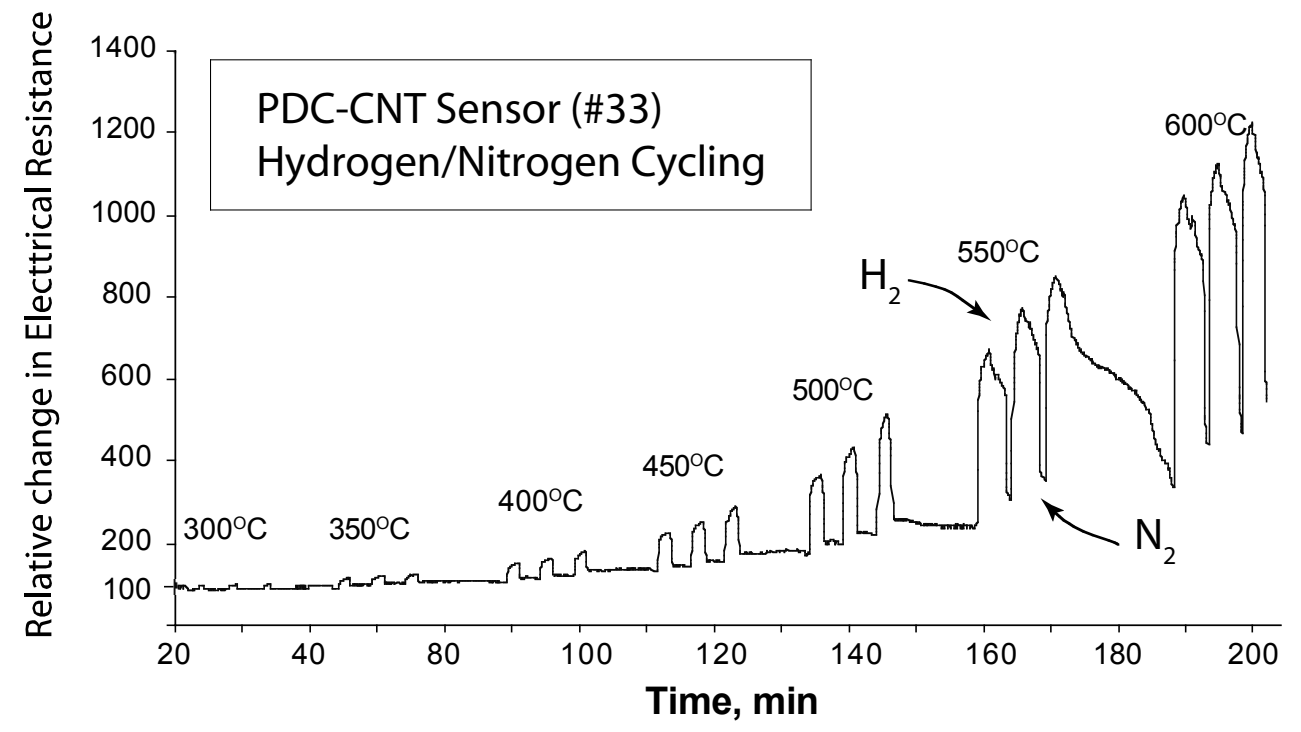

Figure 9: The sensitivity of the PDC-CNT sensor when cycled between hydrogen and nitrogen at one atmospheric pressure. Note the increasing sensitivity at high temperatures.

The results in Fig. 9 show the dramatic influence of hydrogen atmosphere on the electrical resistance of the PDC-CNT sensor. The sensitivity increases with temperature, reaching to a change in the resistance by a factor of when the reactor environment is changed from hydrogen to nitrogen. Note that the resistance is higher in 
the presence of hydrogen than in nitrogen atmosphere. When the reactor was cycled between nitrogen and "vacuum" the resistance of the sensor remained unchanged.

Expanded view of the hydrogen-nitrogen cycling results are given in Fig. 10. The resistance increased by a factor of 1.5 at $400^{\circ} \mathrm{C}$ and by nearly 2.0 at $500^{\circ} \mathrm{C}$. The kinetics of the response increases with temperature suggesting a thermally activated mechanism. Note, however, that the sensor response is not entirely reversible since the base resistance continues to increase slightly with every cycle.

\section{PDC-CNT Sensor (\#33) Hydrogen/Nitrogen Cycling}
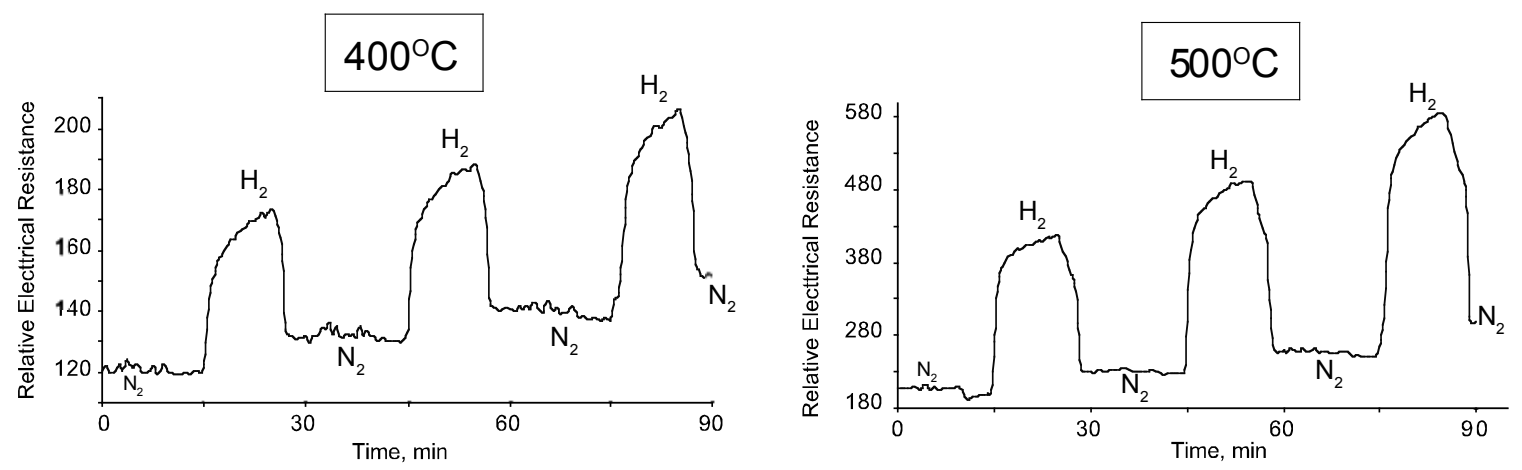

Figure 10: Expanded view of the sensor response at two temperatures. Note that the resistance increases by a factor of 1.5 at $400^{\circ} \mathrm{C}$, and by 2.0 at $500^{\circ} \mathrm{C}$ when the atmosphere is changed from nitrogen to oxygen.

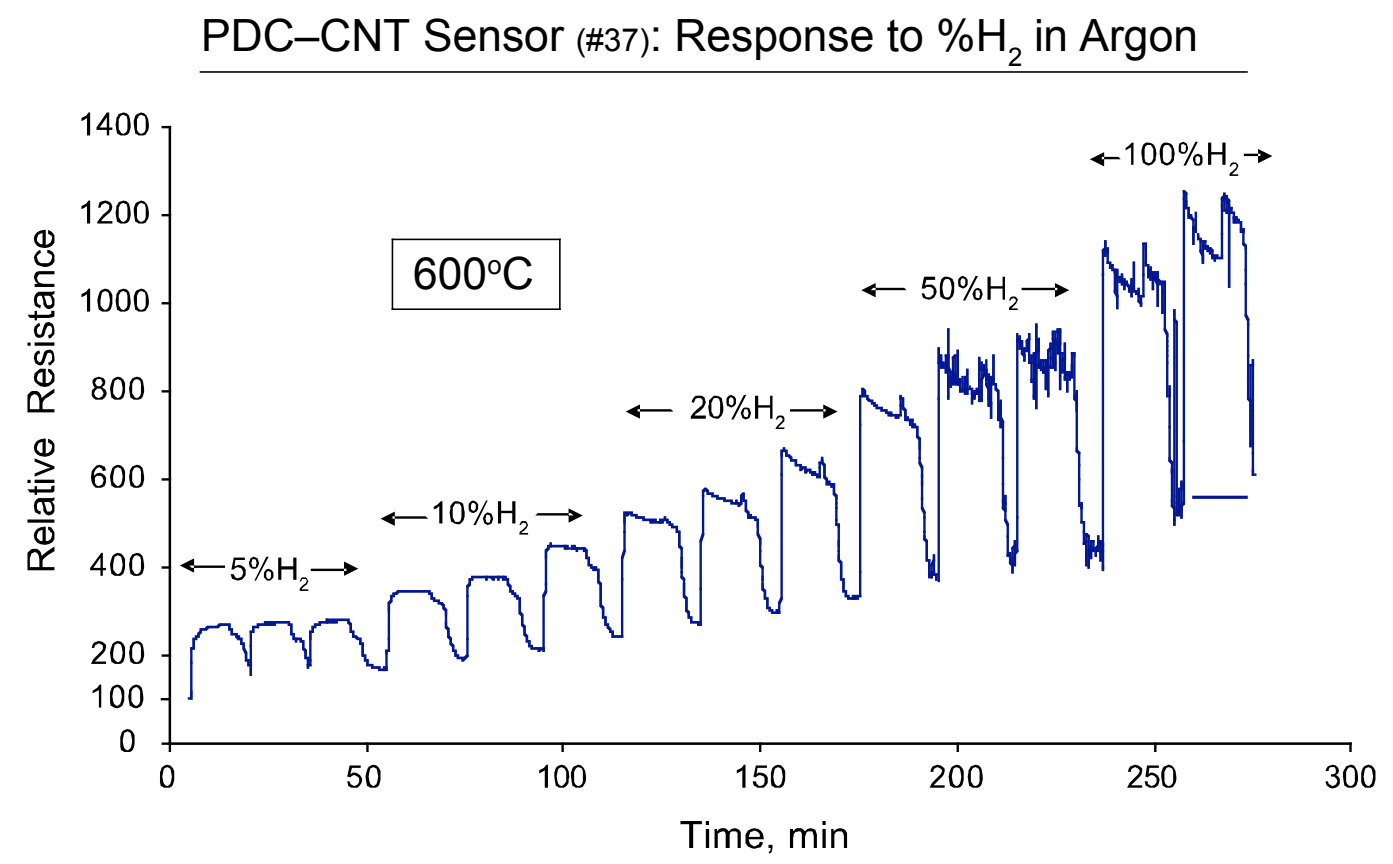

Figure 11: Change in the sensor signal with hydrogen concentration in $\mathrm{H}_{2}$ and Ar mixture in the reactor, at $600^{\circ} \mathrm{C}$. 
The response of the PDC-CNT sensor to different partial pressures of hydrogen, at $600^{\circ} \mathrm{C}$, is shown in Fig. 11. Again, some degree of irreversibility is evident since the base value of the sensor resistance continues to increase with exposure to higher levels of hydrogen. The increase in the resistance of the sensor as a function of hydrogen concentration is plotted in Fig. 11. The change is expressed as a fraction of the base value of 100 as given in Fig. 10.

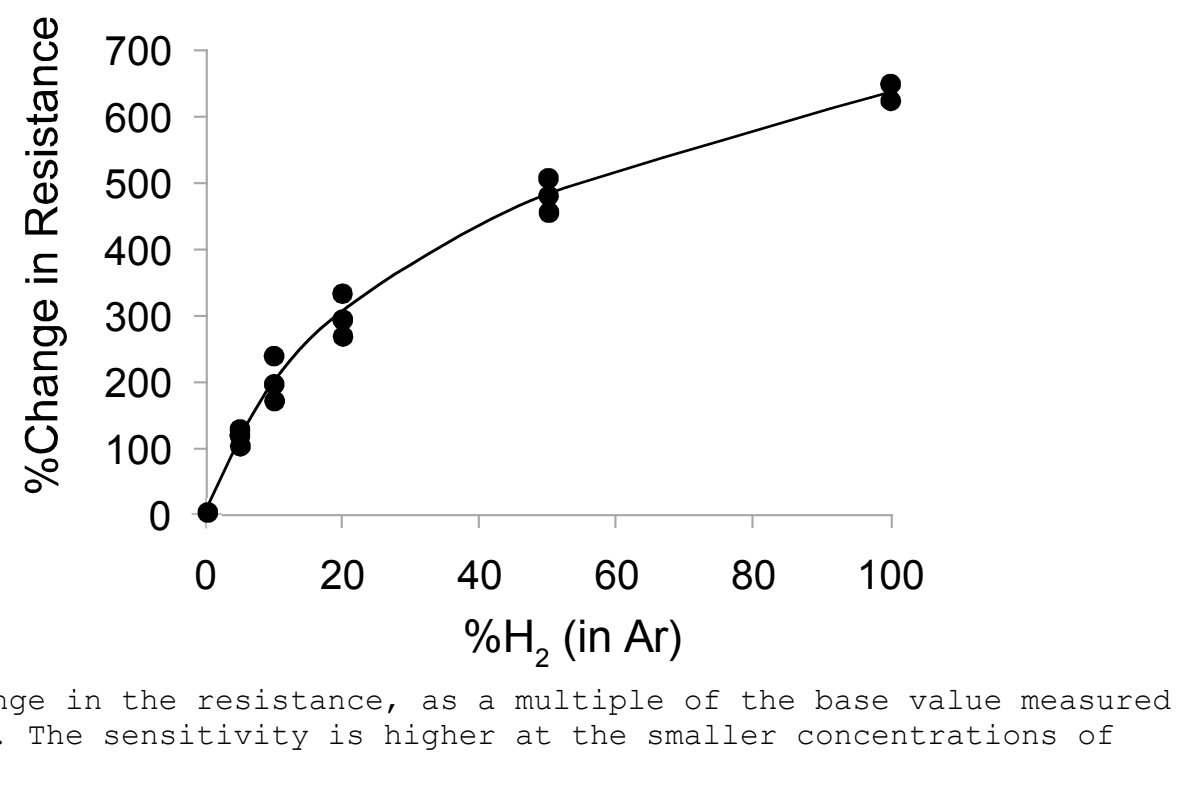

The results in Fig. 12 show a gradually decreasing sensitivity to hydrogen activity as the hydrogen concentration in the reactor rises. This response suggests that the PDC-CNT sensor contains a spectrum of energy states where hydrogen is bonded within the material. It also suggests that the density-of-states decreases with lower binding energies, assuming that the states with the higher binding energies are filled first upon exposure to hydrogen.

\section{R1.3: $\mathrm{CH}_{4}$ and CO Sensitivity of PDC-CNT Sensors}

In addition to hydrogen the PDC-CNT sensors also respond to methane and carbon-monoxide. These results are given in Figs 13 and 14, on the following page. These experiments were carried out by cycling between one atmospheric pressure of the gas with evacuation of the reactor to a pressure of less than 10 torr.

The high sensitivity of the sensor to both methane and to carbon-monoxide is remarkable. The sensitivity to methane is nearly the same as to hydrogen. The sensitivity to $\mathrm{CO}$ is somewhat less. However, the shape of the response to these three species is different, as becomes evident by inspecting Figs 10,13 and 14. The response to $\mathrm{CO}$ is unusual in that the recovery of the resistance upon evacuation of the reactor is delayed: at first the resistance remains unchanged and then abruptly begins to recover. It is also to be noted that in all instances, the resistance of the sensor increases upon exposure to the gaseous species. 


\section{PDC-CNT (\#35): Sensitivity to Methane}

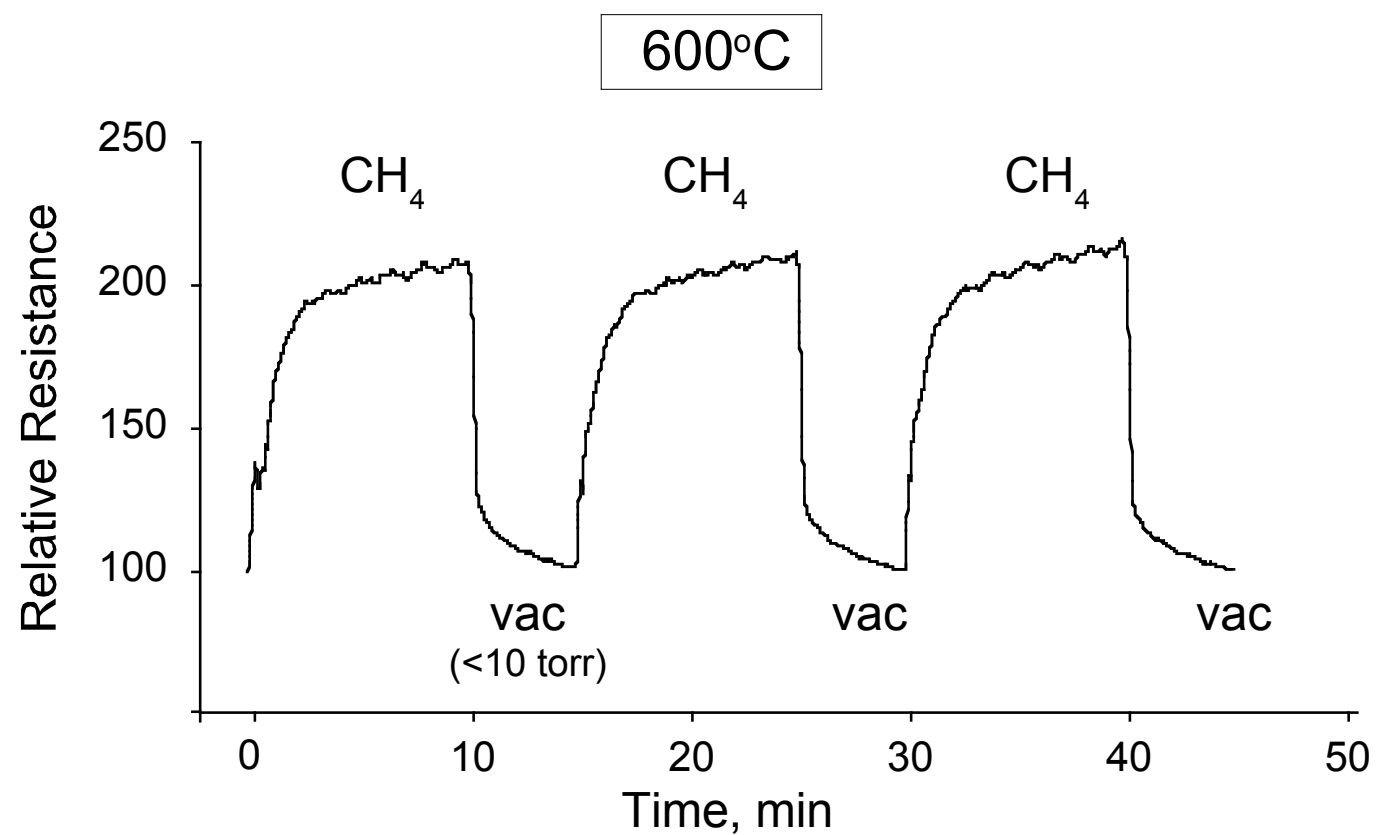

Figure 13: The response of the PDC-CNT sensor to methane at one atmospheric pressure, and at $600^{\circ} \mathrm{C}$. The overall magnitude of the response is similar to that of hydrogen, although the shape and the kinetics of the response are different.

\section{PDC-CNT (\#39): Sensitivity to Carbon-Monoxide}

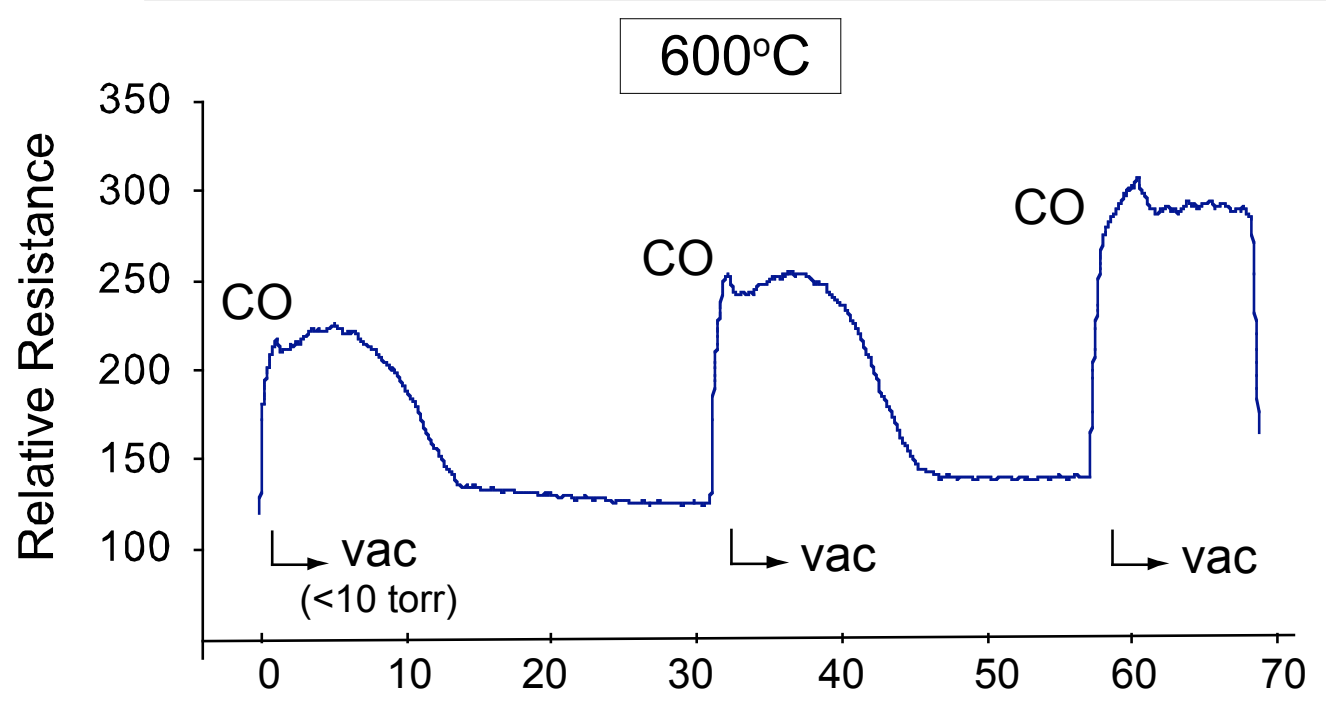

Time, $\min$

Figure 14: The response of the PDC-CNT sensor to CO at one atmospheric

pressure. The delayed recovery of the resistance upon evacuation of the reactor is an unusual feature of the response. 


\section{R1.4: Other Results from the CNT-Paper Based Sensors}

\section{Uncoated CNT Sensor}

A question remained whether or not the monolayer coating of the polymer derived SiCN was a factor in the sensing behavior of the CNT paper. This question was answered by testing uncoated CNT sensor, and the results compared to the results from the PDC-CNT sensor which have been reported in the preceding three sections.

These experiments consistently yielded negative results: the resistance of the uncoated CNT changed by less than $10 \%$ upon exposure to hydrogen over the entire temperature range (ambient to $600^{\circ} \mathrm{C}$ ). Furthermore the response was erratic and noisy, and lacking in a pattern. In comparison the PDC-CNT sensors responded with a change of up to $300 \%$ in their resistance upon exposure to hydrogen. Examples of results from Uncoated-CNT specimen is given in Figs 15 and 16.

Figure 15 shows the resistance of the CNT paper to change by less than $10 \%$ upon exposure to hydrogen at $500^{\circ} \mathrm{C}$, which is nearly 30 times weaker response than was obtained with PDC-CNT sensors which had been coated with a monolayer of polymer derived $\mathrm{SiCN}$.

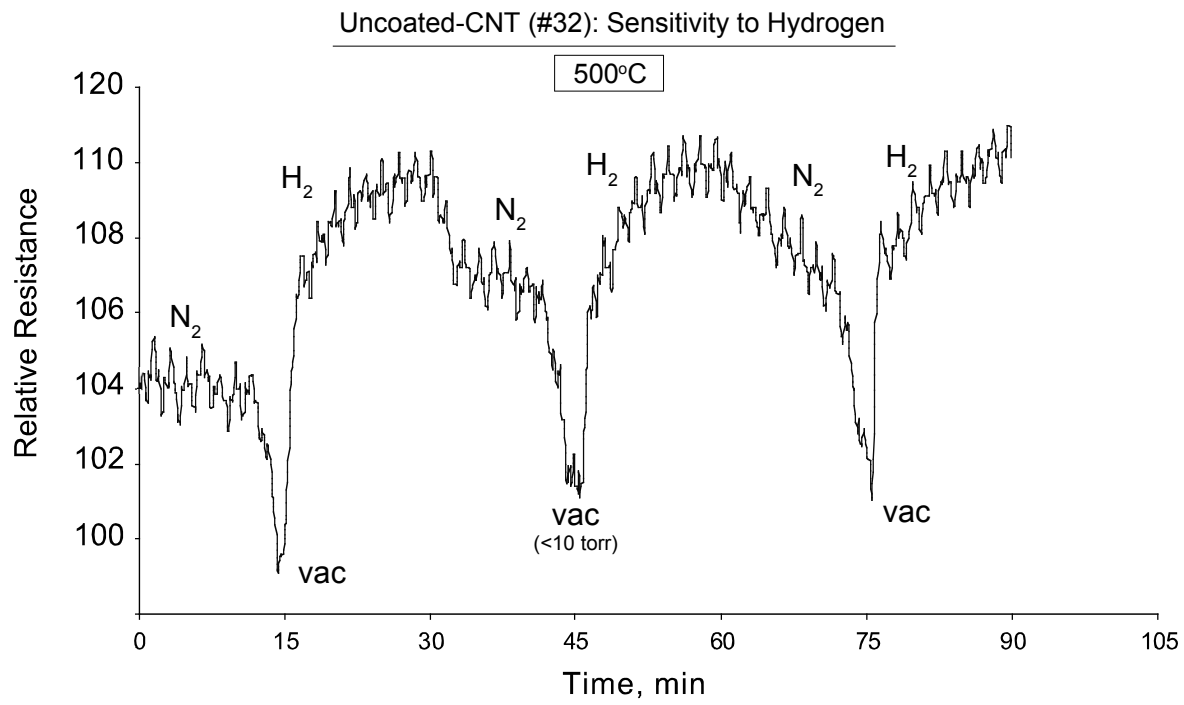

Figure 15: The response of plain, uncoated CNT paper to hydrogen at $500^{\circ} \mathrm{C}$. The response is much weaker than for PDC coated CNT: the change in resistance in the above figure is approximately 10\%, whereas PDC-CNT yielded a change of nearly $300 \%$.

Figure 16 on the following page shows the response of uncoated CNT paper to different activities of hydrogen at $600^{\circ} \mathrm{C}$. A comparison of these results with those for PDC-CNT, as given in Fig. 11, immediately shows the viability of PDC-CNT as a hydrogen sensor and the unfeasibility of uncoated CNT as a hydrogen sensor. 
Uncoated-CNT (\#38): Sensitivity to Hydrogen-Argon Mixtures

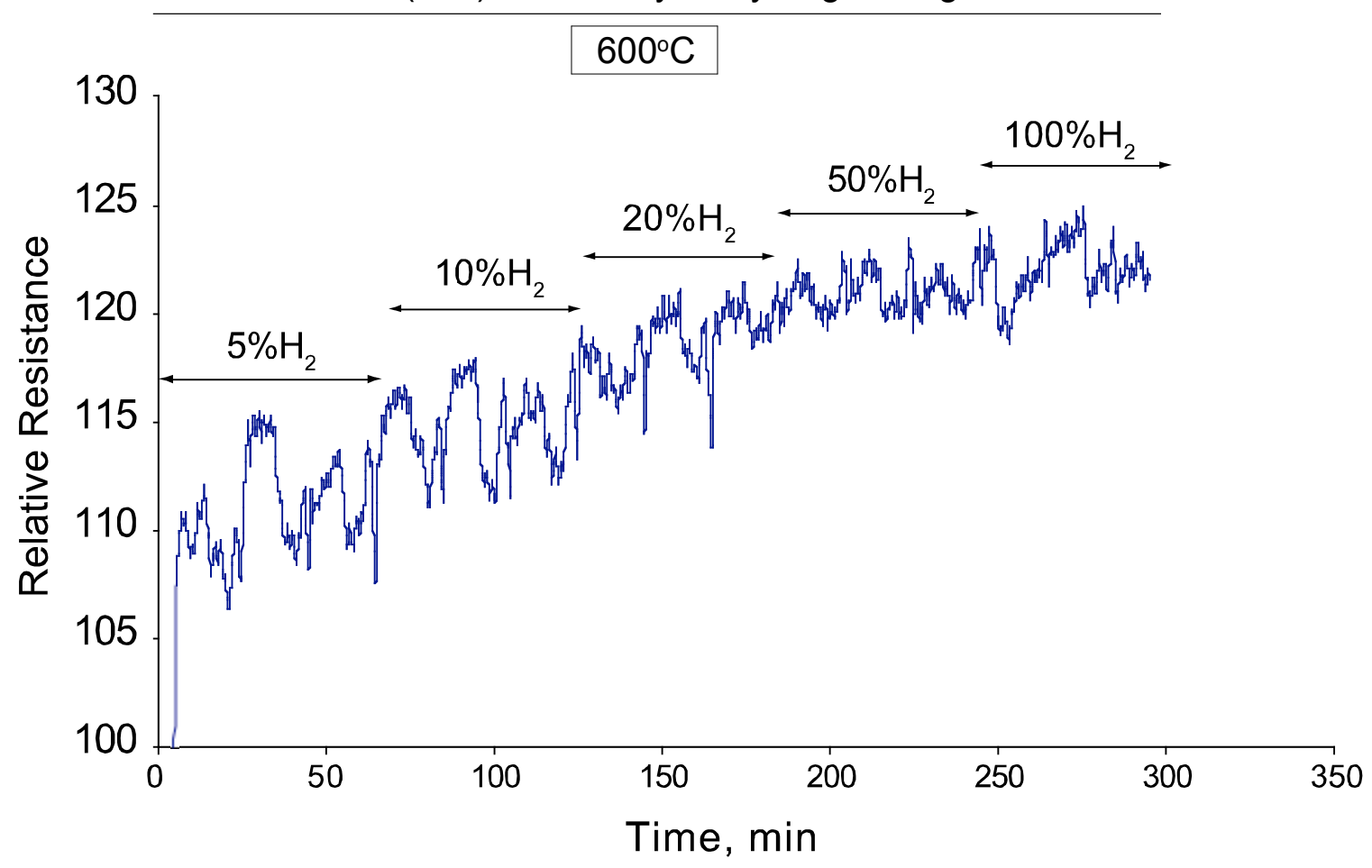

Figure 16: The response of plain, uncoated CNT specimen to hydrogen at different activities at $600^{\circ} \mathrm{C}$. Note the comparison with PDC-CNT in Fig. 11. The response here is not only incoherent it is much weaker than in PDC-CNTs (the change in resistance here is less than $10 \% \mathrm{vs}$. several hundred percent for the PDC-CNT sensor).

\section{Response of Pd Coated PDC-CNT Sensor}

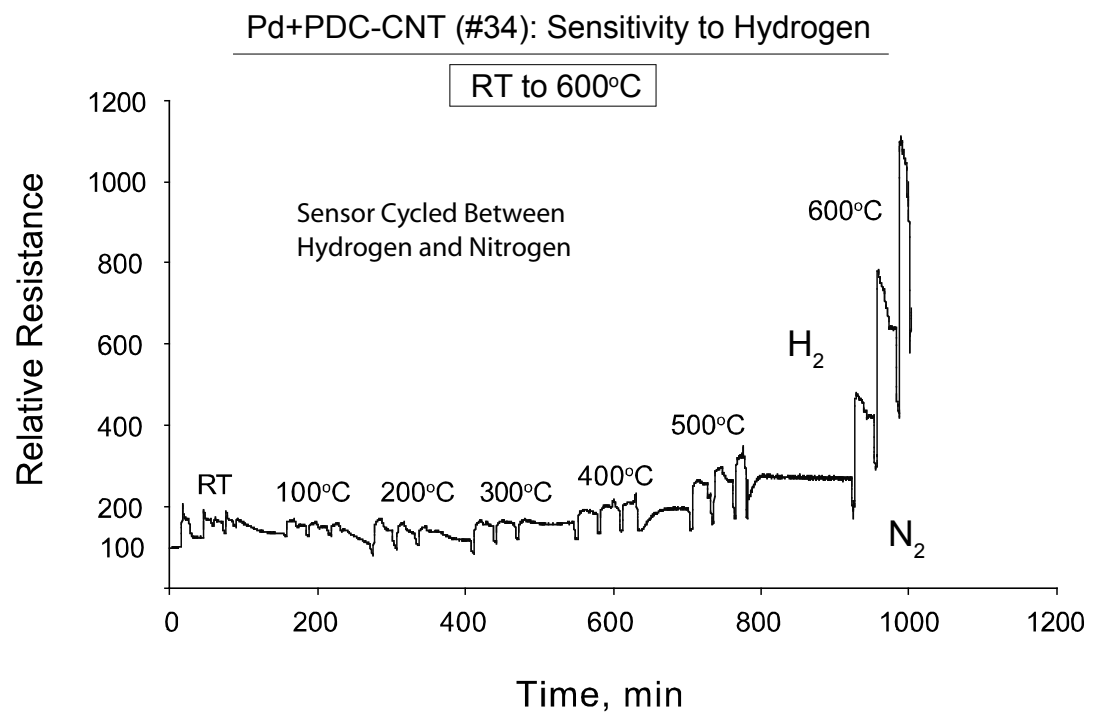

Figure 17: Response of a Pd coated PDC-CNT sensor. The response is erratic is compared to the results from PDC-CNT sensor given in Fig. 9. 
The response of the Pd coated PDC-CNT sensor is given in Fig 17. These results should be compared with the equivalent data from PDC-CNT that were given in Fig. 9. While the sensitivity is approximately equivalent the results from PDC-CNT (in

Fig. 9) are more reproducible, and behaved. However, the Pd coated sensor has some sensitivity to hydrogen at room temperature, which the PDC-CNT sensor does not.

\section{R2: Hydrogen Sensitivity of Thin Films of PDC-SiCN}

The investigation of the hydrogen sensitivity of thin films of PDCs faced considerable barrier in the preparation of samples. Various substrates had to be explored in order to find the one that did not react with the thin film during processing. Zirconia substrates gave the best results. While we had assumed that polished surfaces would yield better results, it was discovered, inadvertently, that the films grown on rough surfaces of zirconia had greater sensitivity of hydrogen, presumably because the roughness increased the surface area of the films. Nevertheless it was difficult to obtain reproducible results, even though thin films showed promise as hydrogen sensors as illustrated by the results in Fig. 18.

\section{Cyclic Resistance Response of SiCN Thin Film in Air and Hydrogen Flow $\left(300^{\circ} \mathrm{C}\right)$}

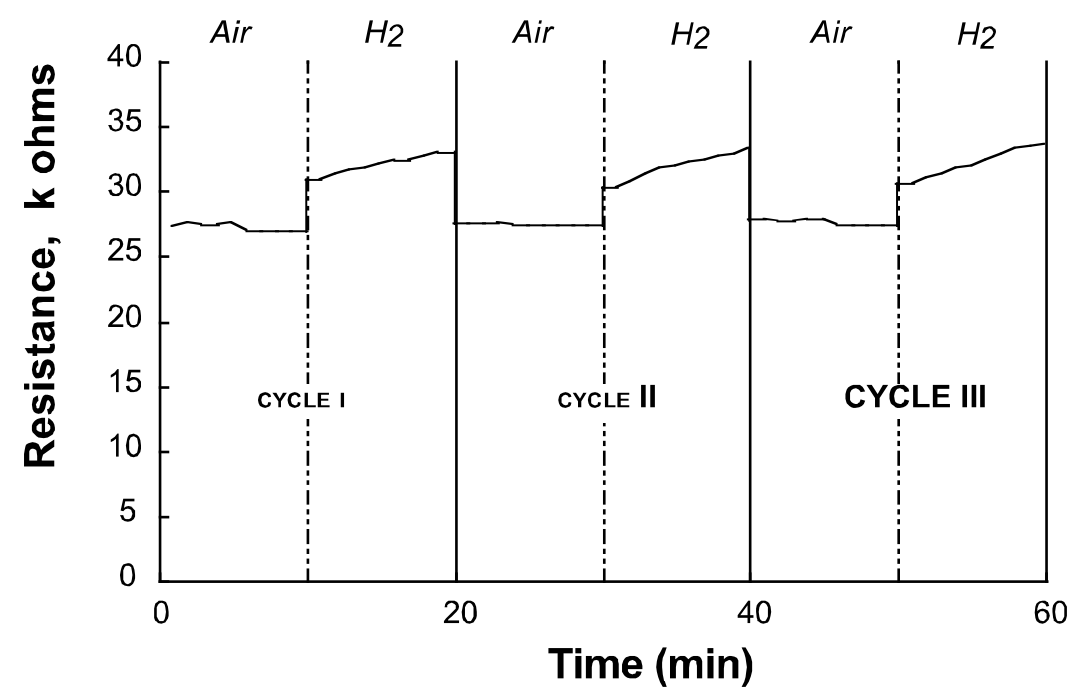

Figure 18: Thin film of SiCN-PDC deposited on a zirconia substrate as a hydrogen sensor.

An unusual result from the thin film sensor was the direction of the change in resistance changed when the temperature was increased to $600^{\circ} \mathrm{C}$, the change of resistance was reversed, that is the resistance decreased in the presence of hydrogen. Thermoelectric power experiments were carried out which showed that the SiCN thin film changed from n-type to p-type semiconductor at higher temperatures. 


\section{R3: MEMS Scale Free Standing Sensors made from SiCN-PDCs}

\section{R3.1 Overview}

Considerable effort was devoted to the development of techniques to measure the resistivity of SiCN-PDC at elevated temperatures. Two experimental barriers were overcome: (i) lithographic methods for making "H" shaped specimens, about $3 \mathrm{~mm}$ in height and 100-200 $\mu \mathrm{m}$ thick, and (ii) metallic interconnects that would be stable at high temperatures. Great success was achieved in measuring the electrical properties of PDCs at temperatures up to $1350^{\circ} \mathrm{C}$.

Since the "H" shaped specimens are thick and, therefore possess a very low surface to volume ratio, it was not expected that its resistance would change significantly as a result of the adsorption of hydrogen on its surface from the atmosphere. However, the experiments for hydrogen sensitivity of the electrical resistance gave remarkable results. In addition to very significant hydrogen sensitivity, the results were high reproducible, and there was unnoticeable drift in the electrical behavior. Furthermore, the electrical sensitivity to hydrogen continued up to $1000^{\circ} \mathrm{C}$, the highest temperature for the reactor system that had been designed for this project. This surprising result is perhaps the most exciting finding from this research grant.

The following sections begin with a brief description of the measurements of the electrical conductivity of $\mathrm{SiCN}$, which is followed by the results, using the same specimens, for hydrogen sensitivity of the electrical properties.

\section{R3.2 Electronic Conductivity of SiCN at High Temperatures}

Polymer derived $\mathrm{SiCN}$ is semiconductor. However, unlike crystalline semiconductor which exhibit a characteristic Arrhenius behavior with single values activation energy, the SiCN shows behavior that is characteristic of polymers, which is described by the Variable Range Hopping mechanism.

The two main results from the work are given on the following page. Figure 19 gives the change in the conductivity with temperature of the SiCN samples. Figure 20 shows the influence of composition of the SiCN samples (principally the nitrogen to oxygen ratio) on the electronic conductivity. A detailed discussion of these results is published in the doctoral thesis of H.-Y. Ryu from the University of Colorado at Boulder, 2006.

Briefly, the results in Fig. 19 show that the electronic conductivity increases with temperature proving semiconductive behavior. Semiconductivity in crystalline materials, such as silicon, is determined by a band structure which is fairly specific to the crystal structure and the doping chemistry. The band gap gives rise to Arrhenius behavior. In amorphous materials, such as the PDCs the semiconductivity is often explained in terms of Mott's Variable Range Hopping mechanism. The analysis of the data in Fig. 19 shows adherence to the $\mathrm{VRH}$ model in the lower temperature range with a transition to Arrhenius behavior at the higher temperatures. The band gap for the Arrhenius nature is approximately $0.5 \mathrm{eV}$. 
Figure 19 shows that the conductivity of the PDCs is highly sensitive to composition, that is it behaves like a doped semiconductor. The mechanism for this electronic structure is not presently understood.

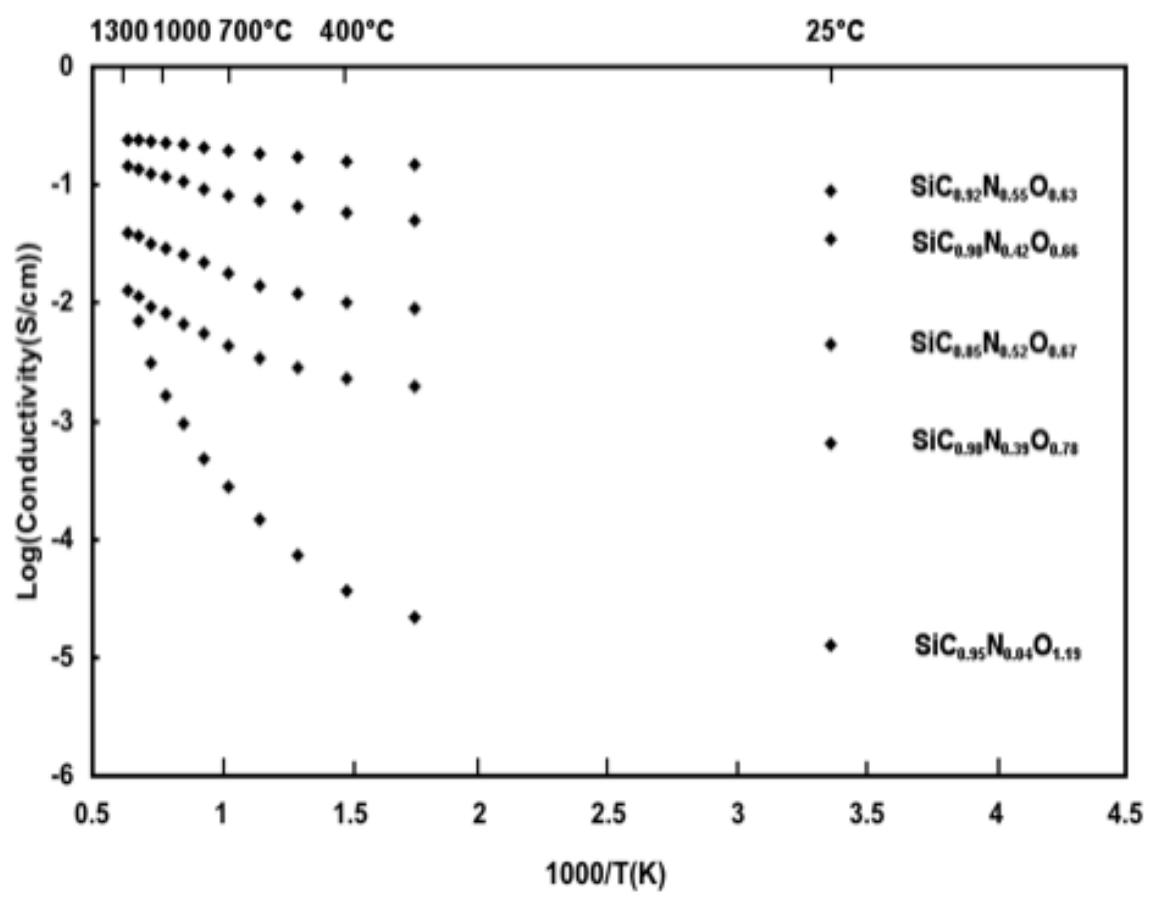

Figure 19: The temperature dependent conductivity of SiCN samples with varying compositions. Note the wide range of electronic conductivity ranging over five orders of magnitude. The influence of composition is more specifically addressed in Fig. 20.

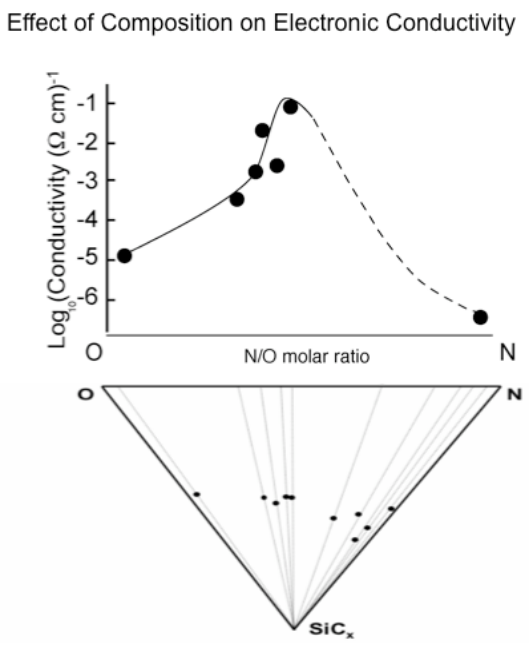

Figure 20: The influence of composition on the electronic conductivity of SiCN samples. The highest conductivity is obtained at the mid-point of $\mathrm{N}-\mathrm{O}$

composition where each is present in equal molar concentrations. 


\section{R3.3 Hydrogen Sensors Made from Free-Standing PDC-MEMS}

Overview.

PDC-MEMS have a much smaller surface area than the PDC-CNT samples, less than $2 \mathrm{~m}^{2} \mathrm{~g}^{-1}$ as compared to $\sim 500 \mathrm{~m}^{2} \mathrm{~g}^{-1}$. Since hydrogen sensing is a surface area phenomenon, PDC-MEMS had not been expected to have gas-sensing properties. However, in trial runs, the PDC-MEMS yielded the extraordinary result of having significant sensitivity of its resistivity to hydrogen exposure. Although the sensitivity was less than that of PDC-CNT specimens, the response was much more stable, reversible, and extended to $1000^{\circ} \mathrm{C}$, the highest temperature where the measurements were made.

The hydrogen sensitivity of PDC-MEMS suggests the ability of hydrogen to diffuse into the material and affect its electronic structure. Apparently significant diffusion is possible even at ambient temperature.

Even though, we did not have the opportunity to study selectivity, that is, sensitivity to different gaseous species, we expect the PDC-MEMS to be more selective than PDC-CNT specimens because of a differential between the diffusivity of the gaseous species in the bulk MEMS specimens. Therefore, the PDC-MEMS are expected to be more selective in their response to hydrogen, methane and carbon-monoxide than PDC-CNT sensors.

The composition of the PDC-MEMS specimens corresponded to those of the SiCNO specimens that had the highest electronic conductivity, as described in Fig. 20, that is, where nitrogen and oxygen has nearly equal molar concentration, with the silicon to carbon molar ratio being approximately 1:0.95.

A Typical Result

The result given below, in Fig. 21, shows a typical response of he PDC-MEMS sensor. The sensor was $125 \mu \mathrm{m}$ thick. Note the high degree of reproducibility and the response time of less than five minutes. This result was obtained at $600^{\circ} \mathrm{C}$. Results from other temperatures are given in the following pages.

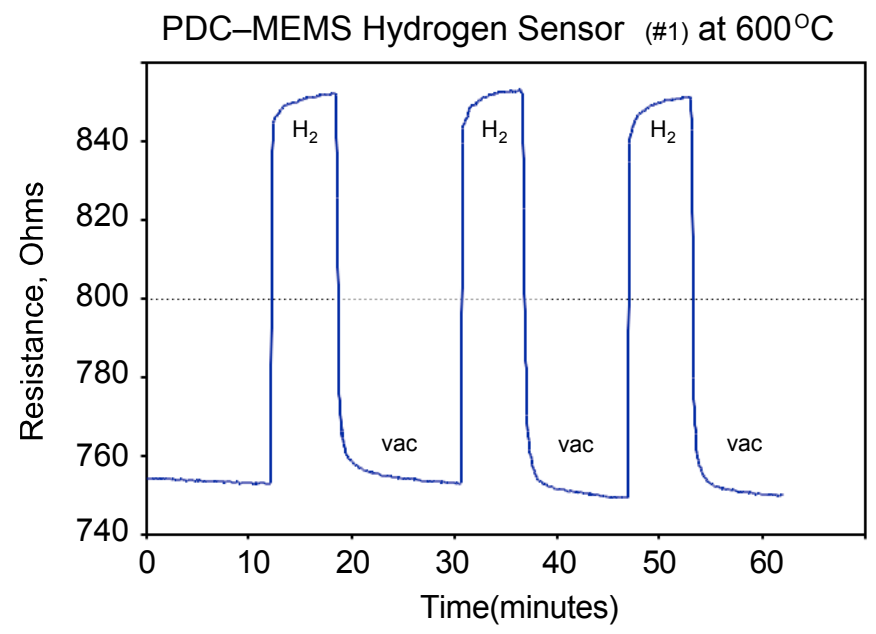

Figure 21: Response of a PDC-MEMS sensor to hydrogen at $600^{\circ} \mathrm{C}$. 
Results from Ambient up to $1000^{\circ} \mathrm{C}$

The result given in Fig. 21 varied slightly from sample to sample, presumably due to some variability in the thickness of the sample. In this section we report measurements taken from a sample with a thickness of $90 \mu \mathrm{m}$.

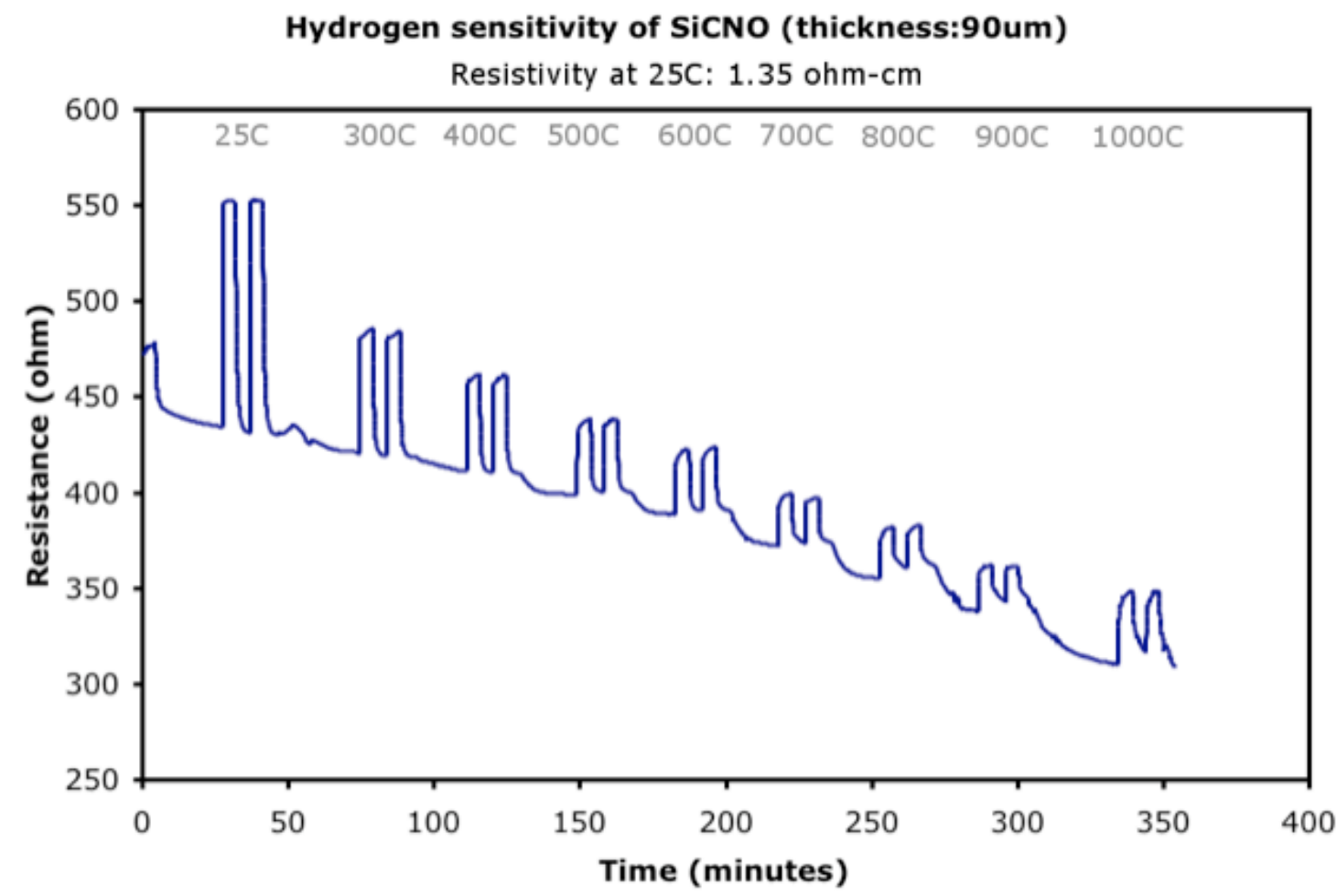

Figure 22: The cyclic response of a PDC-MEMS sensor from ambient up to $1000^{\circ} \mathrm{C}$.

Note that like the PDC-CNT sensor, the PDC-MEMS sensor also show an increase in resistance upon exposure to hydrogen. However, they are different in how the base resistance of the sensor changes with temperature. In the case of PDC-MEMS as seen here, the base resistance decreases as the temperature is increased, which is typical of semiconductive behavior. The PDC-CNT samples, on the other hand showed an increase in the base resistance at higher temperature, which is characteristic of metallic behavior. Therefore, it is to be concluded that the mechanism for the change in the resistance with hydrogen exposure is different for these two types of materials. The fact that PDC-MEMS show higher degree of reversibility, although lower sensitivity to hydrogen, is a reflection of different operating mechanism in the two types of sensors.

The graphs in Fig. 23 given on the following page, give an expanded view of the hydrogen response at various temperatures as shown in Fig. 22. Again while the change in the resistance is small, about $15 \%$ at $1000^{\circ} \mathrm{C}$, the results have higher reliability and reproducibility than was the case in the PDC-CNT sensors, which exhibited a much higher sensitivity to hydrogen. 

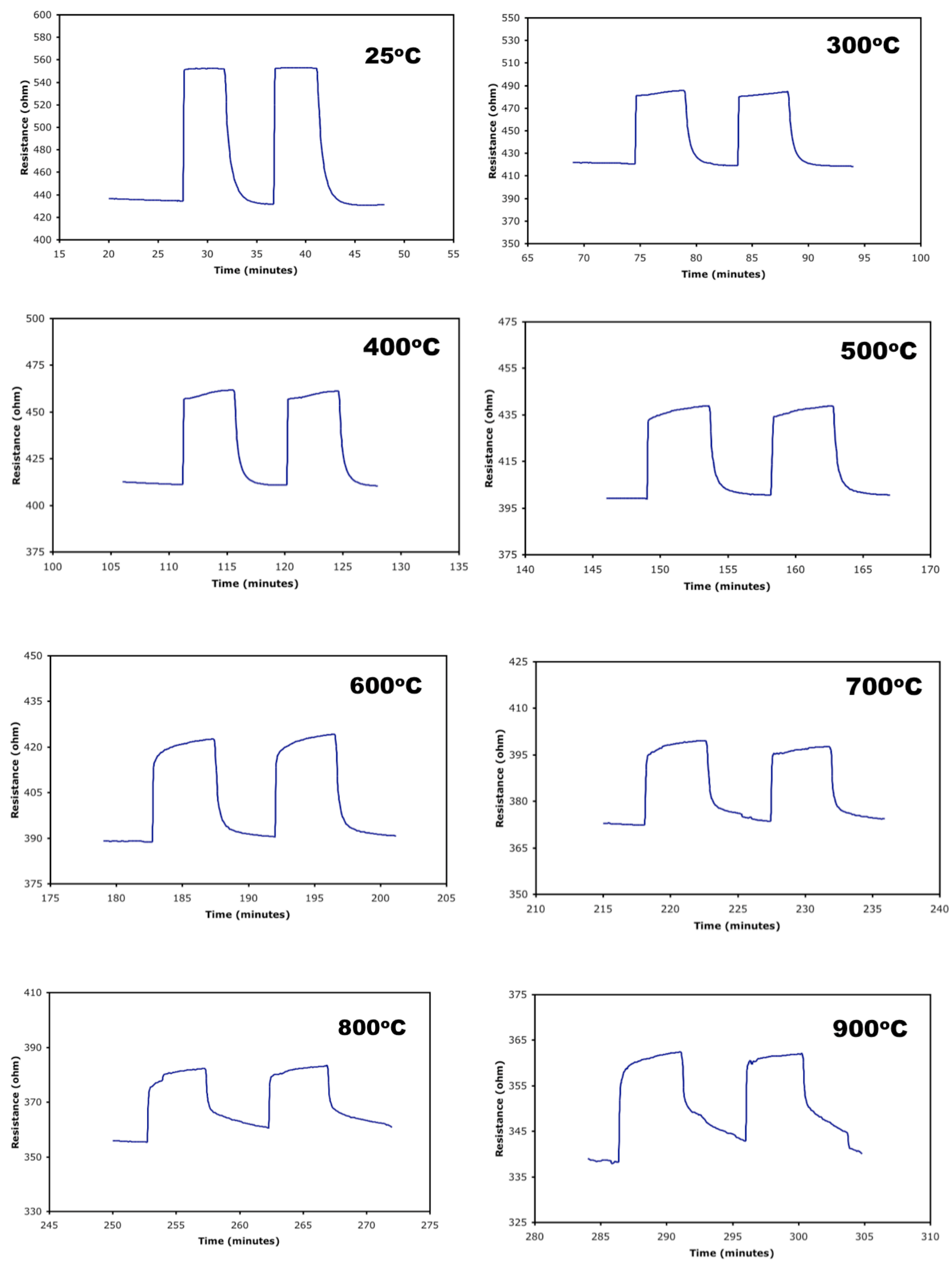


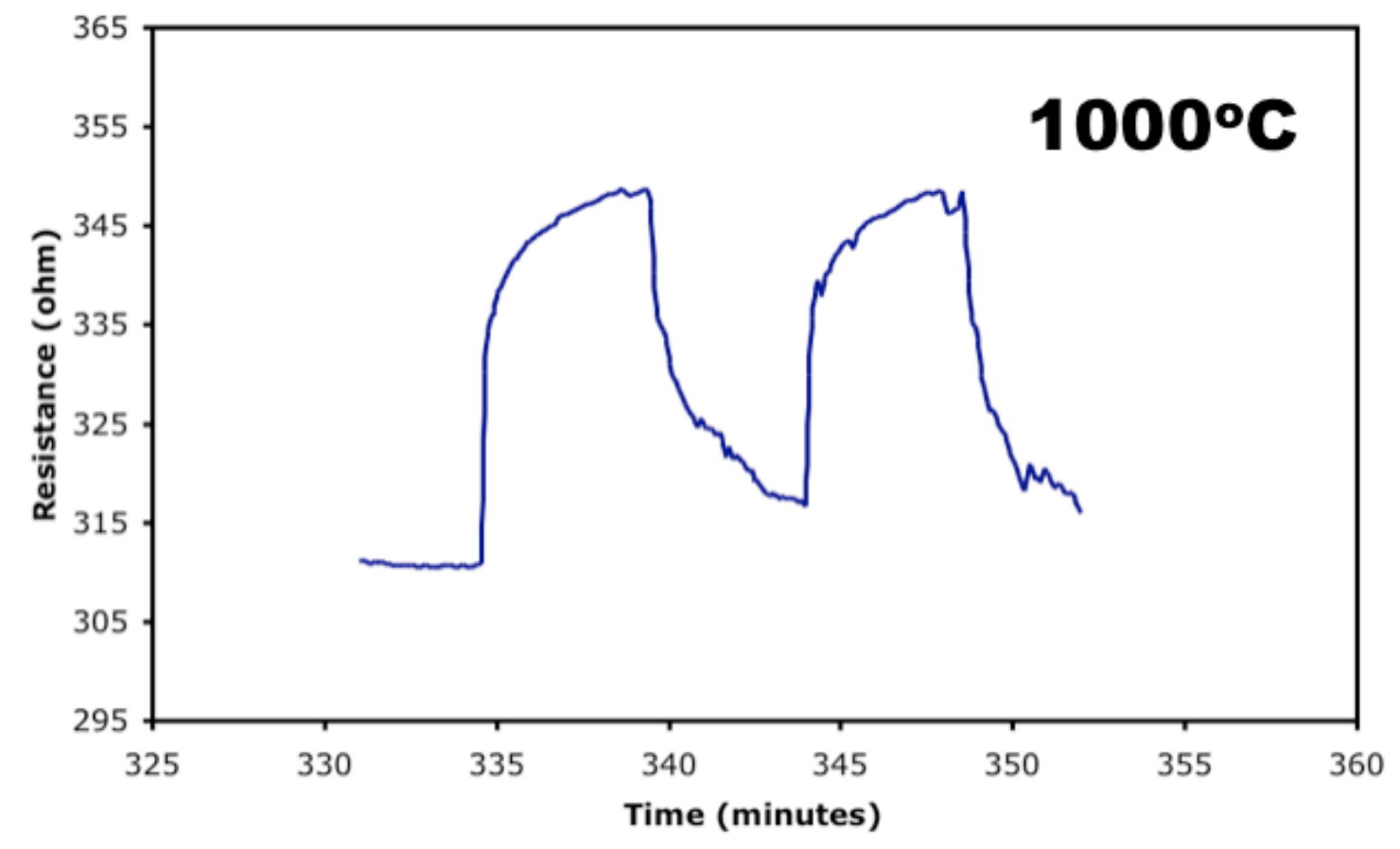

Figure 23: Expanded views of the hydrogen response of the PDC-MEMS sensor from ambient up to $1000^{\circ} \mathrm{C}$. Note that the sensor responds in less than five minutes, and, more importantly, to the same level when hydrogen is reintroduced into the reactor.

\section{R4: PtPd-PDC-CNT as a Catalyst for Hydrogen Generation}

\section{R4.1: Overview}

The hydrogen sensor results proved that PDC-CNT has a much higher catalytic activity that a specimen made from uncoated CNTs. The presence of silicon in the coating suggested that it catalytic activity could be further enhanced by coating with a monolayer of $\mathrm{Pt}$ and/or $\mathrm{Pd}$. The concept underlying this approach was that $\mathrm{Pt} / \mathrm{Pd}$ would form a monolayer on the surface of the PDC-CNT since silicon form strongly bonded silicides with $\mathrm{Pt}$ and $\mathrm{Pd}$. The strong bonding was expected to provide good wetting between the metal and the siliconized surface, leading to a "picoscale" layer of the metal, as illustrated in Fig. 24. Such a monolayer would greatly enhance the Figure-of-Merit (FOM) of the catalyst. The FOM is specified in terms of the catalytic activity per gram of the precious metal. If the metal forms a nanocluster as shown on the left in Fig. 24, then only the atoms on the surface of the cluster participate in catalytic activity: those within the nanocluster do not. Therefore the highest possible FOM is obtained if the metal form a sub-monolayer as shown on the right in Fig. 24.

This second generation sensor is called Pt-PDC-CNT. The hydrogen sensing property of this sensor was inferior to that of the PDC-CNT sensor as shown in the previous section (see Fig. 17). However, the Pt-PDC-CNT catalyst showed remarkable promise for hydrogen generation. These experiments that were carried out with alkaline 
solutions of sodium borohydride are briefly summarized here. The work is published the Journal of Power Sources, and a patent has been filed. The published work is listed in Bibliography.

NanoScale

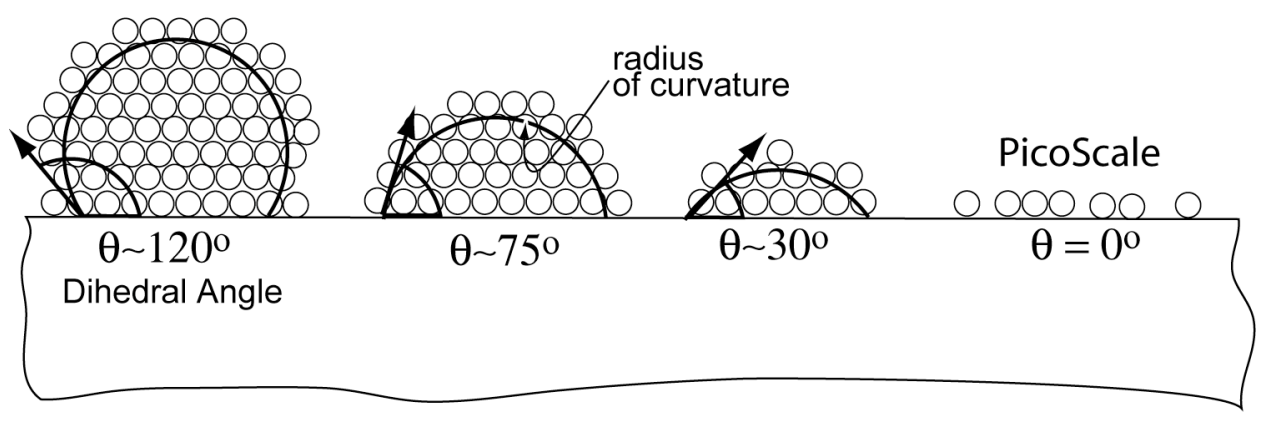

Figure 24: The influence of contact angle on the surface to volume ratio of the cluster. Elemental, or picoscale dispersion of the metal atoms can be obtained if the contact angle approaches zero.

\section{R4.2 Analysis of Hydrogen Generation from Sodium Borohydride}

The rate of hydrogen generation from alkaline $(\mathrm{pH} 13)$, aqueous solution of sodium borohydride was measured as a function of the molar concentration of $\mathrm{NaBH}_{4}$. Typical data set, showing the hydrogen produced as a function of time is shown in Fig. 25.

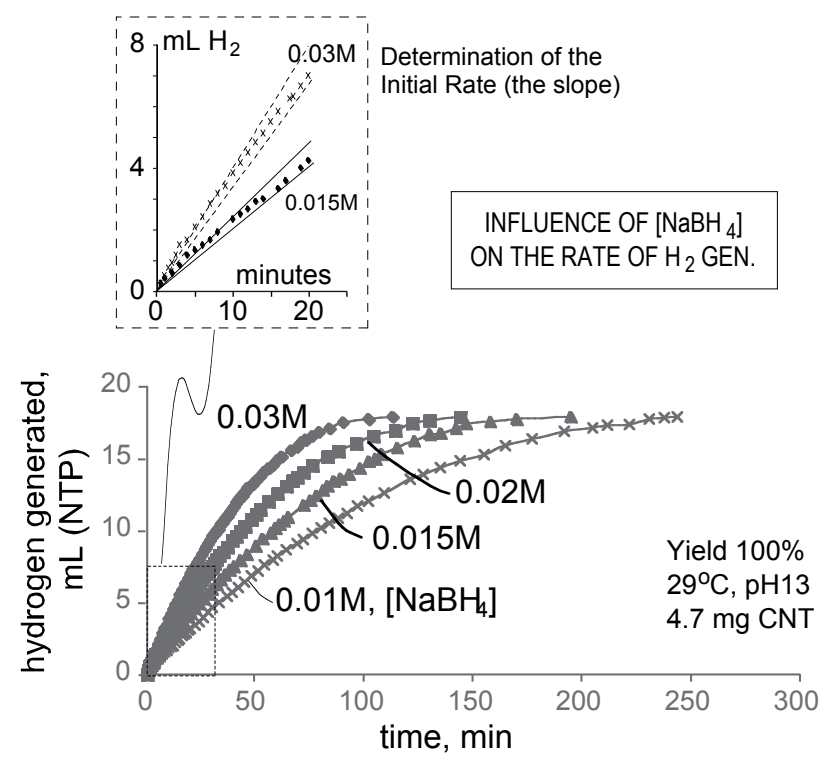


The data were analyzed in terms of a bi-metal atom complex, $M_{1}$ and $M_{2}$, interacting via an electronically conducting substrate

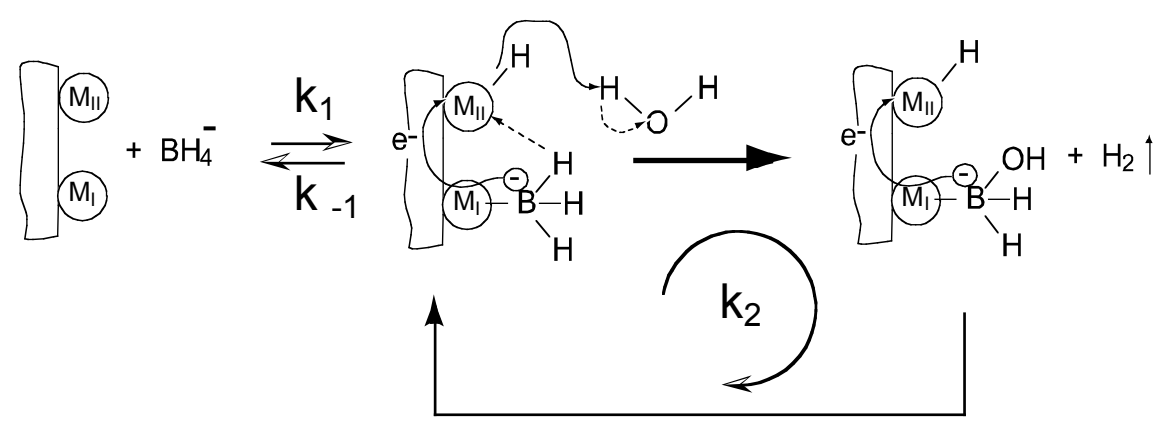

Figure 26: The proposed mechanism for catalytic production of $\mathrm{H}_{2}$ from an aqueous solution of $\mathrm{NaBH}_{4}$.

The analysis of the mechanism leads to the following equation for analyzing the reaction kinetics of hydrogen generation:

$\frac{1}{\left(d n_{H_{2}} / d t\right)}=\frac{1}{K_{1}} \cdot \frac{1}{\left[\mathrm{NaBH}_{4}\right] g_{m e t}}+\frac{1}{K_{2}} \cdot \frac{1}{g_{m e t}}$

Here $K_{1}$ is the rate constant for first-order reaction and $K_{2}$ the rate constant for zero-order reaction. The exact definitions of the parameters in the above equation are:

$\left[\mathrm{NaBH}_{4}\right] \quad$ Molar concentration of $\mathrm{NaBH}_{4}$ in the solution (in $\mathrm{mol} \mathrm{L}^{-1}$ ).

$n_{H_{2}} \quad$ Moles of hydrogen generated from the solution of sodium borohydride.

$g_{\text {met }} \quad$ Total metal content in grams in the solution.

$K_{1} \quad$ Experimental first order rate constant in units of $\mathrm{mol} \mathrm{H}_{2} \mathrm{~min}^{-1} \mathrm{~g}_{\mathrm{met}}{ }^{-1}$ $\left[\mathrm{NaBH}_{4}\right]^{-1}$.

$K_{2} \quad$ Experimental zero order rate constant in units of $\mathrm{mol} \mathrm{H}_{2} \mathrm{~min}^{-1} \mathrm{~g}_{\mathrm{met}}{ }^{-1}$.

The rate constants were then determined by plotting the experimental value for the left hand side of Eq. (1) vs $\left[\mathrm{NaBH}_{4}\right]^{-1}$. The slope of the linear fit to the data gives the value for the first order rate constant, while the intercept of the straight line extrapolated to $\left[\mathrm{NaBH}_{4}\right]^{-1}=0$, gives the rate constant for the zero-order reaction. The plot for these measurements is shown in Fig. 27. 


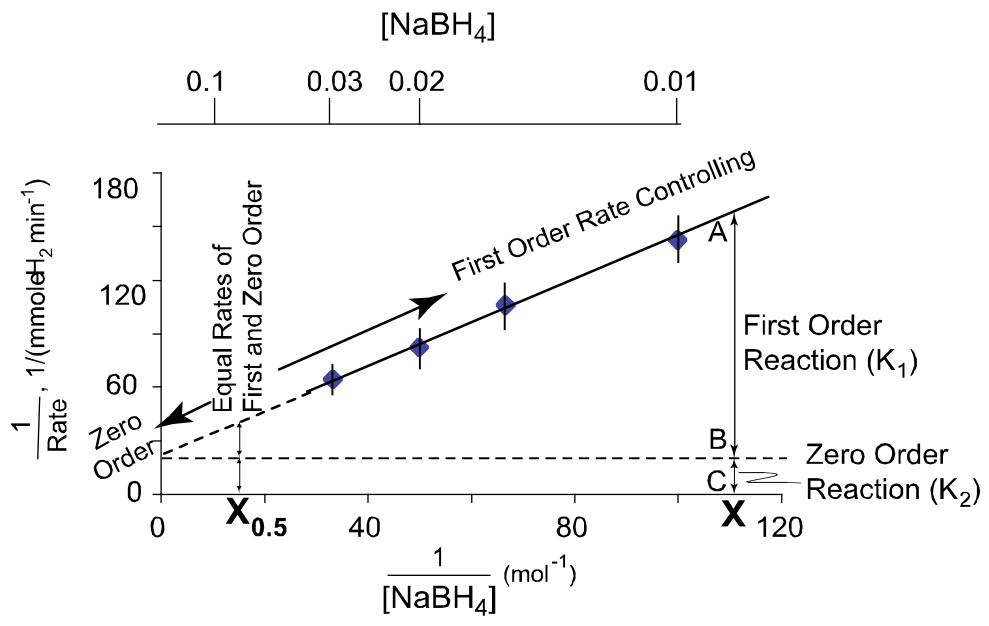

Figure 27: A kinetic plot of H2 release data from Fig. 25 according to the prediction from Eq. (1).

\section{R4.3 The Figure-of-Merit (FOM): A Comparison}

The FOM for the Pt-PDC-CNT catalyst is compared to the data from literature in Fig. 28. Even though this catalyst equals or exceeds the performance for other catalysts, further enhancement from the use of thinner CNT-paper is expected since the metal trapped within the paper is unable to participate in hydrogen generation (because the hydrogen bubbles released within the paper are unable to escape).

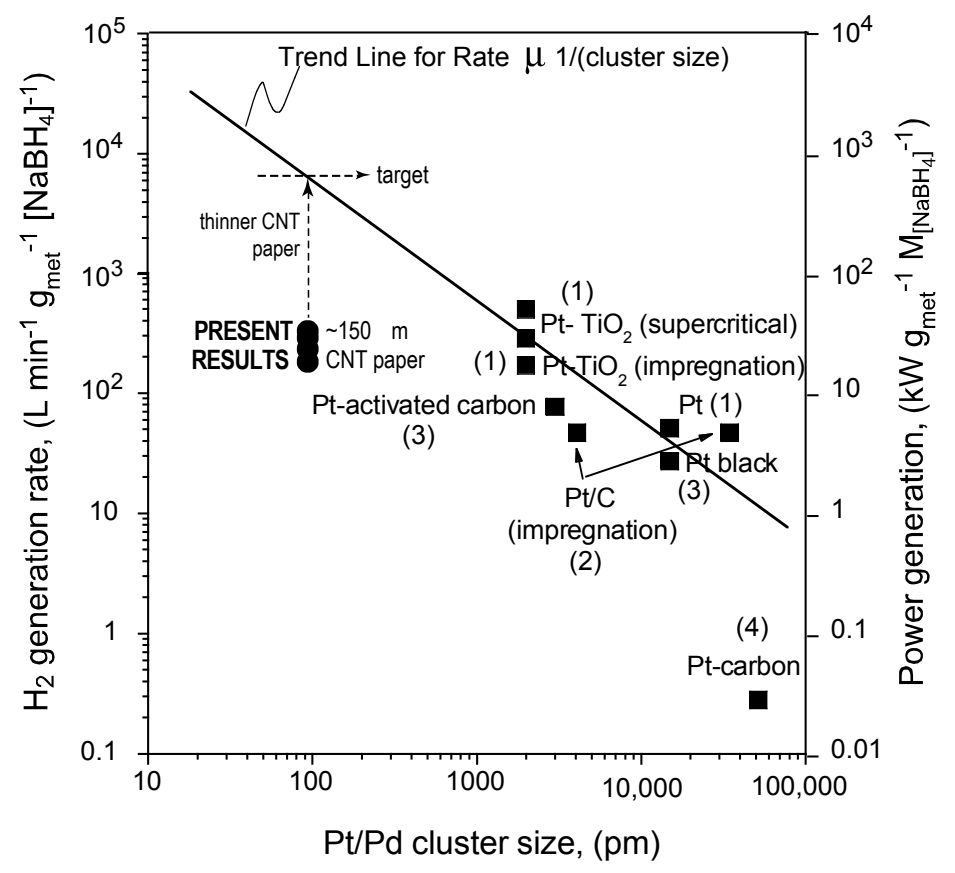

Figure 28: A plot of the figure of merit for the catalyst as a function of the cluster size of the metal atoms. 


\section{Conclusions}

The work in this project has demonstrated that polymer-derived silicon carbonitride ceramic (PDC-SiCN) based materials represent a new paradigm in advancement of energy technologies that are related to sensing, and catalysis of hydrogen. For example the high temperature hydrogen sensing capability, where the resistance of the sensor changes reversibly upon cyclic exposure to hydrogen at $1000^{\circ} \mathrm{C}$ cannot be achieved in any other material. The SiCN-based catalyst for generating hydrogen from sodium borohydride has the potential of achieving a figure of merit that is one hundred times greater than that of any known materials.

The work has demonstrated that PDC-SiCN can be used in two ways: as self-standing, bulk material in the shape of a MEMS device, or as an ultrathin coating on a high surface area structure, for example CNT-paper. The MEMS devices can be made by simple lithographic process used in polymer lithography. These devices are appropriate for high temperature hydrogen sensors. The PDC coated CNT paper, is more suitable for applications in hydrogen catalysis. The potential of PDC-CNT for hydrogen catalysis are not limited to hydrogen generation from sodium borohydride, as demonstrated in the present work, but can most likely be extended to anode and cathode applications for fuel cells, and for hydrogen generation in harsh environments. We foresee applications in clean energy from coal, and hydrogen generation from cycles in reactors that require high temperatures and sulfuric acid.

Future and continued developments of technologies that emerge from these novel PDC-based materials require a much higher level of investment both in basic research of the underlying science of the properties that have been demonstrated here, and in the application of these materials into building energy devices and systems. This high promise is all the more significant because complex properties are achieved in PDCs by the manipulation of the molecular and the nanostructure of simple and environmentally benign elements such as carbon, silicon, nitrogen and oxygen.

The science of the PDCs poses new questions that cut across traditional disciplines. The structure of the PDCs is polymer-like, in the sense they are pseudo amorphous but exhibit strong short range order, but their high temperature properties resemble those of ceramics at very high temperatures. The multifunctionality of the PDCs, which has been amply demonstrated here, depends on the electronic structure of molecular complexes that have still to be understood and modeled. These scientific mysteries will be unraveled only by an intimate collaboration among polymer scientists, metallurgists, ceramists, chemists and physicists. Forging of these unusual collaborations remains a challenge as much for the academic world as for the funding agencies. A deliberate push in such interdisciplinary research is essential.

The engineering opportunities for the PDCs likewise require new alliances. Since these are new materials, which can be tailored to have a multitude of functional and structural properties, their development must be coupled with well-defined applications. An intimate coupling between the science and the applications of the PDCs spells a new paradigm for the development of revolutionary energy technologies. 


\section{Bibliography}

1. H.-Y. Ryu, "Semiconductive Behavior and the Fabrication of a $\mathrm{p}-\mathrm{n}$ Junction Diode from Amorphous Polymer-Derived-Ceramics", Ph.D. Thesis, Department of Mechanical Engineering, University of Colorado at Boulder, Boulder, CO, 2006.

2. "PicoScale Catalyst for Hydrogen Generation from $\mathrm{NaBH}_{4}$ ", R. Peña-Alonso, A. Sicurelli, E. Callone, G. Carturan and R. Raj, Journal of Power Sources, Vol. 165, 315-323 (2007).

3. “A novel micro glow plug fabricated from polymer-derived ceramics: in situ measurement of high-temperature properties and application to ultrahigh-temperature ignition" Liew LA, Bright VM, Raj R, Sensors \& Actuators A-Physical, Vol. 104 (3) : 246-262 (2003).

4. “Ceramic MEMS - New Materials, Innovative Processing and Future Applications", L. Liew, W. Zhang, Linan An, S. Shah, R. Lou, Y. Liu, T. Cross, K. Anseth, V. Bright, J. W. Daily and R. Raj, Bulletin of the American Ceramic Society, Am. Cer. Soc. Bull., Vol 80[5], 25-30 (May 2001).

5. "Hydrogen Sensitivity of the Resistance of Polymer Derived Ceramic MEMS up to $1000^{\circ} \mathrm{C} ", \mathrm{H} .-\mathrm{Y}$. Ryu and R. Raj, to be submitted.

6. “Gas Sensor Properties of Silicon Carbonitride Coated Bucky Paper at Elevated Temperature", A. Anal and R. Raj, to be submitted.

7. “High Temperature Semiconductive Properties of Polymer Derived Silicon Carbooxynitride", H.-Y. Ryu and R. Raj, to be submitted.

8. “A p-n Junction Diode Constructed from Boron Doped Polymer Derived Silicon Carbooxynitride", H.-Y. Ryu and R. Raj, to be submitted. 